\title{
Structural Plasticity of Intrinsically Disordered LEA Proteins from Xerophyta schlechteri Provides Protection In Vitro and In Vivo
}

\author{
Mariana A. Silva Artur ${ }^{1 * t}$, Juriaan Rienstra ${ }^{1}$, Timothy J. Dennis ${ }^{2}$, Jill M. Farrant ${ }^{2}$, \\ Wilco Ligterink ${ }^{1}$ and Henk Hilhorst ${ }^{1}$ \\ ${ }^{1}$ Laboratory of Plant Physiology, Wageningen University, Wageningen, Netherlands, ${ }^{2}$ Department of Molecular and Cell \\ Biology, University of Cape Town, Cape Town, South Africa
}

OPEN ACCESS

Edited by:

Omar Borsani,

Universidad de la República, Uruguay

Reviewed by:

Alejandra A. Covarrubias, National Autonomous University of

Mexico (Morelos), Mexico

Klára Kosová,

Crop Research Institute (CRI),

Czechia

*Correspondence:

Mariana A. Silva Artur

marianasartur@hotmail.com

tPresent address: Plant Ecophysiology, Institute of Environmental Biology, Utrecht University, Utrecht, Netherlands

Specialty section:

This article was submitted to

Plant Abiotic Stress,

a section of the journal

Frontiers in Plant Science

Received: 30 April 2019 Accepted: 11 September 2019

Published: 10 October 2019

Citation:

Artur MAS, Rienstra J, Dennis TJ,

Farrant JM, Ligterink $W$ and Hilhorst H (2019) Structural Plasticity of Intrinsically Disordered LEA

Proteins from Xerophyta schlechteri

Provides Protection

In Vitro and In Vivo.

Front. Plant Sci. 10:1272.

doi: 10.3389/fpls.2019.01272
Late embryogenesis abundant (LEA) proteins are essential to the ability of resurrection plants and orthodox seeds to protect the subcellular milieu against irreversible damage associated with desiccation. In this work, we investigated the structure and function of six LEA proteins expressed during desiccation in the monocot resurrection species Xerophyta schlechteri (XsLEAs). In silico analyses suggested that XsLEAs are hydrophilic proteins with variable intrinsically disordered protein (IDP) properties. Circular dichroism (CD) analysis indicated that these proteins are mostly unstructured in water but acquire secondary structure in hydrophobic solution, suggesting that structural dynamics may play a role in their function in the subcellular environment. The protective property of XsLEAs was demonstrated by their ability to preserve the activity of the enzyme lactate dehydrogenase $(\mathrm{LDH})$ against desiccation, heat and oxidative stress, as well as growth of Escherichia coli upon exposure to osmotic and salt stress. Subcellular localization analysis indicated that XsLEA recombinant proteins are differentially distributed in the cytoplasm, membranes and nucleus of Nicotiana benthamiana leaves. Interestingly, a LEA_1 family protein (XsLEA1-8), showing the highest disorder-to-order propensity and protective ability in vitro and in vivo, was also able to enhance salt and drought stress tolerance in Arabidopsis thaliana. Together, our results suggest that the structural plasticity of XSLEAs is essential for their protective activity to avoid damage of various subcellular components caused by water deficit stress. XsLEA1-8 constitutes a potential model protein for engineering structural stability in vitro and improvement of water-deficit stress tolerance in plants.

Keywords: intrinsic disorder, late embryogenesis abundant proteins, plant desiccation tolerance, resurrection plants, Xerophyta

\section{INTRODUCTION}

Water availability is one of the major environmental factors that affect plant growth, development and productivity. During their life cycle, plants may endure periods of environmental drought and, depending on the duration of such periods, it may lead to irreversible structural damages affecting plant development and survival. Most higher plants undergo programmed water loss during their 
life cycle, which may occur in organs such as pollen, spores and seeds (Bewley, 1995; Scott, 2000). A group of about 135 angiosperm plant species have been described as "resurrection plants" for their ability to tolerate the loss of $80 \%$ to $95 \%$ of cellular water and resume photosynthetic activity and growth within hours after rehydration (Oliver et al., 2000; Scott, 2000; Porembski, 2011; Farrant et al., 2015). It is likely that desiccation tolerance (DT) appeared in the plant lineage during the transition from water to land, became confined to reproductive structures as plants evolved, and reappeared in vegetative structures of angiosperm resurrection plants by redirecting pre-existing genes and pathways to survive in the dry state (Ingram and Bartels, 1996; Oliver et al., 2000; Rensing et al., 2008; Farrant and Moore, 2011; Wodniok et al., 2011; Gaff and Oliver, 2013).

Recently, the genome of the resurrection species Xerophyta schlechteri $^{1}$ (Behnke et al., 2013) has been sequenced (Costa et al., 2017). X. schlechteri is a monocot species belonging to the Velloziaceae family, and it is distributed mainly in southern African regions and inhabits rocky terrain or inselbergs in exposed grasslands (Porembski and Barthlott, 2000; Mello-Silva et al., 2011; Farrant et al., 2015). X. schlechteri is a resurrection monocot species, phylogenetically related to most important grass crops from the Poaceae family, and understanding its DT opens opportunities to apply this knowledge to improve drought tolerance in crops (Farrant et al., 2015; Costa et al., 2017).

Several mechanisms of responses to desiccation in X. schlechteri leaves have been correlated with its resurrection phenotype (Farrant et al., 2015). Among the essential adaptive mechanisms to survive loss of water, the accumulation of protective molecules has been shown to be an essential component of DT at the subcellular level. These molecules include sucrose, raffinose family oligosaccharides (RFOs) and LEA proteins which are thought to act, inter alia, as osmoprotectants in the formation and stability of the so-called cytoplasmic glassy state (Leprince et al., 1993; Hoekstra et al., 2001; Buitink and Leprince, 2004; Vicré et al., 2004; Farrant et al., 2012).

LEA proteins were first discovered due to their accumulation during late stages of embryo development of cotton seeds, coinciding with their acquisition of DT (Dure et al., 1981; Galau et al., 1986; Dure et al., 1989), and their characteristic stressinduced expression has led to the hypothesis that these proteins are involved in stress responses mediated by abscisic acid (ABA) (Galau et al., 1986). LEA transcription appears to be inducible by $\mathrm{ABA}$ and osmotic stress and is evident upon drying below $60 \%$ to $40 \%$ RWC, a common pattern observed in both seeds and resurrection plants (Illing et al., 2005; Leprince and Buitink, 2010; Costa et al., 2017). Interestingly, the translation of some LEA proteins has been shown to occur a few hours or even days after their transcription, suggesting regulation at the transcriptional and translational levels (Galau et al., 1987; Hughes and Galau, 1991; Espelund et al., 1992; Chatelain et al., 2012; Verdier et al., 2013). In addition to transcriptional and translational regulation, some LEA proteins were shown to undergo posttranslational modifications

\footnotetext{
The Xerophyta viscosa (Baker) plants used by Costa et al. (2017) have been classified as Xerophyta schlechteri (Baker) N.L. Meneses (Behnke et al., 2013).
}

(PTMs), reflecting the complexity of the regulation of these proteins at various levels (Riera et al., 2004; Boudet et al., 2006).

Several LEA proteins are assumed to be intrinsically disordered proteins (IDPs) considering their ability to undergo order to disorder transitions in different in vitro environments (Soulages et al., 2002; Mouillon et al., 2006; Shih et al., 2010; Popova et al., 2011; Hincha and Thalhammer, 2012; Hundertmark et al., 2012; Shih et al., 2012; Rivera-Najera et al., 2014; Cuevas-Velazquez et al., 2016; Bremer et al., 2017; Cuevas-Velazquez et al., 2017). This interesting physicochemical characteristic allows LEA proteins to form homo- and heterodimers and to interact with multiple targets (Tolleter et al., 2007; Popova et al., 2015; CuevasVelazquez et al., 2016; Hernandez-Sanchez et al., 2017). The ubiquitous distribution of LEA-like proteins in bacteria and invertebrates suggests that similar protective mechanisms of DT involving LEA proteins have evolved across different life forms (Tunnacliffe and Wise, 2007; Costa et al., 2016).

The myriad of secondary structures enables LEA proteins to play multiple roles in abiotic stress tolerance, constituting an essential footprint of DT in seeds and resurrection plants (Maia et al., 2011; Costa et al., 2017). To further characterize and explore the biochemical, structural, and functional properties of LEA proteins, we cloned the coding sequences of six LEA genes expressed in $X$. schlechteri leaves upon desiccation: XsDHN12, XsLEA1-8, XsLEA4-8, XsLEA4-12, XsLEA6-2, and XsSMP4. We examined the secondary structure of these LEA proteins by circular dichroism (CD) and monitored their folding dynamics in hydrophobic solution. In vitro and in vivo experiments demonstrated that these XsLEAs perform protective roles under desiccation, heat, oxidative, salt, and osmotic stress. The protective activity of XsLEAs seems protein type-specific, with a strong correlation between the ability to form defined secondary structures in vitro and the extent of protection both in vitro and in vivo. XsLEAs are localized in multiple subcellular compartments, such as nucleus, membrane, and cytoplasm, supporting the idea of universal cell protection by LEA proteins. Heterologous expression of XsLEA1-8 in Arabidopsis thaliana leads to higher tolerance to salt and osmotic stress in seedlings and drought in adult plants. Our work sheds new light on the biochemical properties of these stress-responsive proteins and highlights characteristics of LEA proteins that can be useful for bioengineering protein stability in vitro and improving abiotic stress tolerance in crops.

\section{MATERIALS AND METHODS}

\section{In Silico Analysis}

Protein Grand Average Hydropathy was calculated using the GRAVY calculator (http://www.gravy-calculator.de/). Molecular mass and isoelectric point (pI) were calculated with the isoelectric point calculator (IPC) (Kozlowski, 2016). Protparam (http://web.expasy.org/protparam/) was used to analyse amino acid composition and predict protein stability. The percentage of polar residues was calculated with EMBOSS PEPSTATS (https:// www.ebi.ac.uk/Tools/seqstats/emboss_pepstats/). Prediction of the degree of protein disorder was performed using IUpred 
(Dosztányi et al., 2005) and PONDR (http://www.pondr.com/) with default parameters (VLXT predictor). Sequence-specific parameters and prediction of structural qualities of the proteins were predicted with CIDER (http://pappulab.wustl.edu/CIDER/ analysis/) (Holehouse et al., 2017). ANCHOR web server (http://anchor.enzim.hu/) was used to predict the number of disordered binding regions (DBRs), i.e. regions with propensity to undergo folding upon partner-binding with a probability higher than 50\%, and MoRFpred (http://biomine.cs.vcu.edu/ servers/MoRFpred/) was used to predict the number of residues of molecular recognition features (MoRFs). Disorder enhanced phosphorylation predictor (DEPP), also known as DisPhos and available from http://www.pondr.com/cgi-bin/depp.cgi was used to predict phosphorylation sites within the protein sequences (Iakoucheva et al., 2004). Subcellular localization was predicted with PSI (http://bis.zju.edu.cn/psi/), CELLO2GO (http://cello. life.nctu.edu.tw/) and Plant-mPLoc (http://www.csbio.sjtu. edu.cn/bioinf/plant-multi/). Signal peptide predictions were performed with SignalP v. 4.1 Server (http://www.cbs.dtu.dk/ services/SignalP/), PrediSi (http://www.predisi.de/), and TargetP 1.1 Server (http://www.cbs.dtu.dk/services/TargetP/).

\section{Plant Materials and Growth Conditions}

Seeds obtained from mature X. schlechteri plants, collected from Buffelskloof Private Nature Reserve in the Mpumulanga province of South Africa, were sown on potting soil and maintained in greenhouse at the Wageningen University under conditions of $16 \mathrm{~h}$ at $27^{\circ} \mathrm{C}$ during the day and $8 \mathrm{~h}$ at $18^{\circ} \mathrm{C}$ during the night. Dehydration was achieved by withholding water from the pots. Young green leaf tissue was harvested from four individual plants on a daily basis, frozen in liquid nitrogen, and stored at $-80^{\circ} \mathrm{C}$. Nicotiana benthamiana plants used for agro infiltration and $A$. thaliana plants ecotype Columbia-0 used for floral dipping and drought treatments were grown on a mix of $50 \%$ vermiculite and $50 \%$ soil watered three times a week with Hyponex solution (Hyponex Japan, Osaka, Japan http://www.hyponex.co.jp), in a greenhouse with long-day photoperiod cycles (16h light $/ 8 \mathrm{~h}$ dark) at $22^{\circ} \mathrm{C} \pm 2{ }^{\circ} \mathrm{C}$ for 3 weeks. A. thaliana plants used for seed collection were grown on Rockwool blocks (Grodan, the Netherlands) in Hyponex solution under greenhouse conditions (16 h light/8 h dark).

\section{RNA Extraction, cDNA Synthesis and Cloning of XsLEAs}

Total RNA was extracted from leaves of adult X. schlechteri plants 9 days after dehydration using the hot borate protocol (Wan and Wilkins, 1994). cDNA was synthesized using the iScript ${ }^{\mathrm{TM}} \mathrm{cDNA}$ Synthesis Kit (Bio-Rad, Laboratories B.V., The Netherlands) according to the manufacturer's protocol. Primers were designed to include flanking restriction sites, which were in turn flanked with Gateway AttB1 and AttB2 sites (Supplementary table 1). PCR was performed on $X$. schlechteri cDNA with Q5 high-fidelity DNA polymerase (New England Biolabs) and PCR products were purified from gel using Nucleospin Gel and PCR clean-up (Macherey-Nagel). The purified amplicons were cloned into the entry vector pDONr201 using BP Clonase II according to the manufacturer's instructions (Thermo Fisher Scientific) to create pENTr201-LEA and sequenced to confirm the gene sequence.

\section{Construction of Plant Expression Vectors}

For $N$. benthamiana transient gene expression, subcloning from pENTr201-LEA into pGWB606 (Nakamura et al., 2010) was performed with a Gateway LR reaction to produce recombinant p35S::GFP-XsLEAs. Correct reading frame was confirmed by sequencing. For $A$. thaliana heterologous expression, subcloning of the XsLEAs CDS from pENTr201-LEA into the expression vector $\mathrm{pB} 7 \mathrm{WG} 2 \mathrm{RS}$ was also performed with a Gateway LR reaction. The expression vector $\mathrm{pB} 7 \mathrm{WG} 2 \mathrm{RS}$ was made by cloning the RedSeed selection marker ( $p N A P:: D s R e d)$ from pKGW-RedSeed between the left T-DNA border and the Bar resistance gene of pB7WG2 (Karimi et al., 2002) using XbaI and KpnI. Correct insertion of the RedSeed marker was confirmed by sequencing.

\section{Construction of Bacterial Expression Vectors}

For protein expression and purification, XsLEA CDSs were cloned from pENTr201-LEA into bacterial expression vector pDEST17 with a Gateway LR reaction to produce recombinant $\mathrm{N}$-terminal His-tagged proteins (pEXPR17-LEA). The correct reading frame was checked by sequencing. For E. coli stress assays, the XsLEAs were subcloned from pENTr201-LEA to the bacterial expression vector pCDF-Duet (Novagen), which contains two multiple cloning sites (MCSs), using traditional cloning. XsLEA6-2 and XsDHN12 were subcloned to MCS1 using NcoI and EcoRI, while XsSMP4, XsLEA4-8, XsLEA412 , and XsLEA1-8 were subcloned to MSC2 using NdeI and AvrII (New England Biolabs; Supplementary Table 1). In all cases, both pENTr201-LEA and pCDF-Duet were digested with the corresponding enzymes. The fragment containing the $X s L E A$ CDS from the digested pENTr201-LEA was purified by gel extraction (Macherey-Nagel). The digested pCDF-Duet vector was subjected to dephosphorylation (shrimp alkaline phosphatase [rSAP] from New England Biolabs) and purified with a silica column (Macherey-Nagel). The XsLEA fragments were ligated into pCDF-Duet using T4 DNA Ligase (Promega) to create pCDF-LEA. Correct orientation was confirmed by PCR.

\section{Expression and Purification of the Recombinant XsLEAs}

BL21 (DE3) pLysS (Novagen) E. coli expression strain carrying the different pDEST17-LEA vectors were grown overnight in $5-\mathrm{cm}^{3}$ sterile LB medium at $37^{\circ} \mathrm{C}(200 \mathrm{rpm})$. The cultures were inoculated in $1 \mathrm{dm}^{3}$ of sterile LB medium in a $5-\mathrm{dm}^{3}$ Erlenmeyer flask and incubated at $37^{\circ} \mathrm{C}$ with shaking $(200 \mathrm{rpm})$. When an optical density at $600 \mathrm{~nm}\left(\mathrm{OD}_{600}\right)$ of 0.6 was reached $( \pm 3 \mathrm{~h})$, isopropyl $\beta$-D-thiogalactopyranoside (IPTG) was added to a final concentration of $1 \mathrm{mM}$ and incubation continued for 2 $\mathrm{h}$ at $37^{\circ} \mathrm{C}(100 \mathrm{rpm})$ to induce protein expression. The cells were then harvested by centrifugation at $4^{\circ} \mathrm{C}, 10,000 \mathrm{~g}$ for 10 min and the cell pellets were frozen overnight at $-20^{\circ} \mathrm{C}$. The 
cell pellets were then thawed an resuspended in $15 \mathrm{~cm}^{3}$ LysisEquilibration-Wash Buffer (LEW; Macherey-Nagel) containing $50 \mathrm{mM} \mathrm{NaH} \mathrm{PO}_{4}$ and $300 \mathrm{mM} \mathrm{NaCl}$ with a $\mathrm{pH}$ of 8.0 using $\mathrm{NaOH}$. A $1-\mathrm{mg} / \mathrm{cm}^{3}$ lysozyme (Sigma-Aldrich) was added, followed by incubation on ice for $30 \mathrm{~min}$. The cells were lysed by sonication and the lysate was centrifuged for $30 \mathrm{~min}$ at $4^{\circ} \mathrm{C}, 10,000 \mathrm{~g}$. For purification of the His-tagged recombinant LEA proteins from the crude lysate, the Protino ${ }^{\circledR}$ Nickel TED (Ni-TED) Histidine Tag Affinity Purification Kit (MachereyNagel, Germany) was used with standard protocol. The purified His-tagged XsLEAs were subjected to concentration and buffer exchange into $\mathrm{dH}_{2} \mathrm{O}$ using the Amicon Ultra Centrifugal Filters (3K for XsLEA4-8, XsLEA1-8, XsLEA6-2 and XsDHN12, and 30K for XsSMP4 and XsLEA4-12, MWCO, Merck Millipore). Centrifugation was performed at $8,000 \mathrm{~g}$ for $1 \mathrm{~h}$ or $14,000 \mathrm{~g}$ for $15 \mathrm{~min}$ for the $3 \mathrm{~K}$ and $30 \mathrm{~K}$ filters, respectively, at $4^{\circ} \mathrm{C}$ to concentrate the proteins, followed by three washing steps with $12 \mathrm{~cm}^{3}$ of $\mathrm{dH}_{2} \mathrm{O}$ (the same centrifugation parameters were used). Total protein concentration was quantified using the Bradford BioRad Microassay (BioRad USA) according to manufacturer's instructions with bovine serum albumin (BSA; Sigma Aldrich, USA) as a standard. As an additional purification step, making use of the heat stability of most LEA proteins (Boudet et al., 2006), 10 to $15 \mu \mathrm{g}$ of the recombinant proteins were submitted to a $97^{\circ} \mathrm{C}$ treatment for $10 \mathrm{~min}$, centrifuged, and the supernatant was analyzed on a $12 \%$ SDS-PAGE at $90 \mathrm{~V}$ for $2 \mathrm{~h}$ with a Colour Prestained Protein Standard Ladder (New England Biolabs, USA). After electrophoresis, gels were stained with a Coomassie Blue solution ( $2.5 \mathrm{~g} / \mathrm{dm}^{3}$ Coomassie Blue (Sigma-Aldrich), 50\% $\mathrm{v} / \mathrm{v}$ methanol, $10 \% \mathrm{v} / \mathrm{v}$ acetic acid) for $1 \mathrm{~h}$ at room temperature and destained overnight in a solution of $45 \% \mathrm{v} / \mathrm{v}$ methanol and $10 \% \mathrm{v} / \mathrm{v}$ acetic acid prior to visualization.

\section{In-Solution Circular Dichroism Analysis for Secondary Structure}

Circular dichroism (CD) spectra of the six recombinant Histagged LEA proteins were obtained using a JASCO J-810 Spectropolarimeter (JASCO Analytical Instruments, Japan) in $1 \mathrm{~mm}$ path-length quartz cuvettes. Spectral data were recorded from 240 to $190 \mathrm{~nm}$, with 10 accumulations per run using a 0.2 $\mathrm{nm}$ data pitch, $100 \mathrm{~nm} / \mathrm{min}$ scanning speed, $1 \mathrm{~s}$ response time and $1 \mathrm{~nm}$ of band width. To simulate changes in secondary structure, we used $80 \%$ acetonitrile (ACN), $20 \mathrm{mM} \mathrm{NaCl}$, and MiliQ water adjusted with $\mathrm{HCl}$ to $\mathrm{pH} 2.3$ or $\mathrm{pH} 4.0$ as protein solvents. BSA (Sigma-Aldrich, USA) was used as a control for the spectra of an alpha-helical structure, at a concentration of 0.075 $\mathrm{mg} / \mathrm{cm}^{3}$. Measurements of millidegrees obtained from the results were subsequently converted into mean residue $(\theta)$ and plotted against the wavelength range $(\mathrm{nm})$. CD data were fitted using Dichroweb (http://dichroweb.cryst.bbk.ac.uk/html/home.shtml) (Contin, data set 7) (Whitmore and Wallace, 2004) to estimate the secondary structure content.

\section{In Vitro Lactate Dehydrogenase Assays}

Lactate dehydrogenase (LDH) assays were adapted from Reyes et al. (2008). In short, LDH from rabbit muscle (Sigma-Aldrich) was diluted to a final concentration of $200 \mathrm{nM}$ in $25 \mathrm{mM}$ Tris $\mathrm{pH}$ 7.5. The purified XsLEAs or BSA were also diluted to a final concentration of $200 \mathrm{nM}$ in $25 \mathrm{mM}$ Tris- $\mathrm{HCl} \mathrm{pH} \mathrm{7.5.} \mathrm{The}$ mixture of LDH and XsLEA at a molar ratio of 1:1 was submitted to desiccation, heat or oxidative stress. After each treatment, the enzyme and protein mixture was added to a reaction buffer containing $25 \mathrm{mM}$ Tris- $\mathrm{HCl}$ pH 7.5, $2 \mathrm{mM}$ of pyruvate (SigmaAldrich) and $0.15 \mathrm{mM} \mathrm{NADH}$ (Roche) to a final volume of 1 $\mathrm{cm}^{3}$ in $2 \mathrm{~cm}^{3}$ plastic cuvettes and the initial absorbance was measured at $340 \mathrm{~nm}$. The rate of the decrease in absorbance due to the conversion of $\mathrm{NADH}$ to $\mathrm{NAD}^{+}$was determined every $5 \mathrm{~s}$ for $1.5 \mathrm{~min}$ at $25^{\circ} \mathrm{C}$. For the desiccation-induced aggregation assay, $\mathrm{LDH}$ in the presence of each of the purified XsLEAs or BSA were submitted to dehydration in a centrifugal evaporator (Savant ${ }^{\mathrm{TM}}$ SpeedVac ${ }^{\mathrm{TM}}$ Plus SC210A) for $1 \mathrm{~h}$ at room temperature. After dehydration, the initial volume was restored by adding $25 \mathrm{mM}$ Tris- $\mathrm{HCl} \mathrm{pH} \mathrm{7.5,} \mathrm{and} \mathrm{enzyme} \mathrm{activity} \mathrm{was}$ measured as mentioned above. For the thermal inactivation assays, the samples containing each of the six purified XsLEAs or BSA together with $\mathrm{LDH}$ were heated at $42^{\circ} \mathrm{C}$ for $20 \mathrm{~min}$ and cooled down at room temperature for $10 \mathrm{~min}$. Oxidative stress was imposed by incubating the LDH enzyme and XsLEAs or BSA mixtures in $200 \mathrm{mM}$ of $\mathrm{H}_{2} \mathrm{O}_{2}$ (Sigma-Aldrich) at room temperature for $1 \mathrm{~h}$. Each assay was repeated three times with three technical replicates each and statistically significant differences were analyzed with Excel (Microsoft, United States) using Student's $t$-test.

\section{Abiotic Stress Tolerance Assays of E. coli Transformants}

E. coli strain BL21(DE3)RIL (Agilent) was transformed with the pCDF-Duet-LEA vectors. LEA expression was induced with 1 $\mathrm{mM}$ IPTG for $2 \mathrm{~h}$. Cells were diluted to $\mathrm{OD}_{600}=1.0$ and a serial dilution of $5 \mathrm{~mm}^{3}$ was spotted onto LB media containing $350 \mathrm{mM}$ of $\mathrm{NaCl}$ or mannitol. To assess in vivo heat protective function $1 \mathrm{~cm}^{3}$ of LB containing IPTG-induced $E$. coli cells $\left(\mathrm{OD}_{600}=1.0\right)$ was incubated in a water bath at $50^{\circ} \mathrm{C}$ for $30 \mathrm{~min}$, cooled for 10 min at room temperature and then spotted onto LB control plates supplemented with 1.5\% Daishin agar (Duchefa). Serial dilutions at $10,50,100,500$, and 1000 times were used for salt and osmotic stresses, and $0,10,100$ and 1000 times for heat stress assays. The plates were incubated at $37^{\circ} \mathrm{C}$ for $16 \mathrm{~h}$. For the liquid media growth assay, $1 \mathrm{~cm}^{3}$ of cells at $\mathrm{OD}_{600}=1.0$ was diluted 10 times with LB liquid media supplemented with $250 \mathrm{mM} \mathrm{NaCl}$. The cells were kept at $37^{\circ} \mathrm{C}$ and $100 \mathrm{~mm}^{3}$ aliquots were taken every hour for measuring the $\mathrm{OD}_{600}$. Due to the possibility of leaky vector activation, resulting in expression of proteins before induction with IPTG (Grossman et al., 1998; Zhang et al., 2015; Briand et al., 2016), we analyzed and compared the relative growth percentage of the XsLEA strains with the empty vector-carrying strain. The difference in $\mathrm{OD}_{600}$ at time point $x\left(\mathrm{t}_{x}\right)$ between treated and non-treated (control) cultures were used to calculate the relative growth, expressed as $\left[\mathrm{OD}_{\text {treatment }(\mathrm{tx}) /} \mathrm{OD}_{\text {control }(\mathrm{tx})}\right] \times 100$. Each experiment was repeated twice and statistical differences were determined by using the Student's $t$-test in Excel (Microsoft, United States). 


\section{In Vivo Localization of XsLEAs In $N$. benthamiana Leaves}

Agrobacterium tumefaciens strain AGL0, carrying constructs of pGWB606 p35S::GFP-LEAs, was grown in LB medium containing antibiotics and harvested by centrifugation at $4,000 \mathrm{~g}$ for $5 \mathrm{~min}$ at room temperature. The bacteria culture was resuspended in infiltration buffer (10 $\mathrm{mM} \mathrm{MgCl}_{2}, 10 \mathrm{mM} \mathrm{MES,} \mathrm{pH} \mathrm{5.6,} \mathrm{and} 200$ $\mu \mathrm{M}$ acetosyringone) and adjusted to $\mathrm{OD}_{600}=0.6$. The bacterial suspension was incubated at room temperature on a rocking platform for $1 \mathrm{~h}$. Leaves of 3- to 4-week-old $N$. benthamiana plants were infiltrated with $A$. tumefaciens suspension using a needleless syringe and a minimum of three independent agro infiltrations was performed $(n \geq 3)$. Three days after infiltration, two leaves from three independently transformed plants were analyzed for GFP fluorescence under a Leica TCS SP8 HyD confocal microscope (Leica) with an excitation wavelength of $488 \mathrm{~nm}$, and the spectral detection was set between 500 and 557 $\mathrm{nm}$ for GFP, and 642 and $747 \mathrm{~nm}$ for chlorophyll fluorescence. The objective used was $40 \times$ in water immersion.

\section{A. thaliana Transformation and RT-qPCR Gene Expression Confirmation}

The pB7WG2RS p35S::LEA1-8 construct was introduced into A. tumefaciens strain AGL0 and transformed into A. thaliana Colombia-0 (Col-0) using the floral dip method (Clough and Bent, 1998). Using the RedSeed marker, transgenic T1 plants were selected and single T-DNA inserts were identified in the T2. RNA of T3 dry seeds was extracted and $700 \mathrm{ng}$ of RNA was reverse transcribed as described above. RT-qPCR reactions were run on a CFX machine (Bio-Rad). Three technical replicates were used per sample. The reference genes used for data normalization were At4g12590 and At4g34270 (Dekkers et al., 2012). The primers used for RT-qPCR and the obtained $C_{t}$ values are presented in Supplementary Table 2. After confirmation of the expression of XsLEA1-8 in T3 seeds, plants were grown in a complete randomized design containing three biological replicates of at least four plants. Seeds were harvested and used for further experiments.

\section{Seed, Seedling, And Plant Stress Phenotyping}

Germination experiments were performed 10 days after harvest. For control conditions, seeds were sown in square trays on two layers of filter papers saturated with $\mathrm{dH}_{2} \mathrm{O}$, in accordance with
Joosen et al. (2010). For salt and osmotic stress, the filter papers were saturated with $-0.3 \mathrm{MPa} \mathrm{NaCl}$ or $-0.6 \mathrm{MPa}$ mannitol, respectively. After sowing, the seeds were stratified at $4^{\circ} \mathrm{C}$ in the dark for $48 \mathrm{~h}$ and the trays were subsequently moved to $22^{\circ} \mathrm{C}$ under continuous light. To investigate tolerance to deterioration conditions, dry seeds were incubated at $40^{\circ} \mathrm{C}$ at approximately $85 \%$ relative humidity for 3 days, and then transferred to germination conditions at $22^{\circ} \mathrm{C}$ under continuous light. Germination was scored twice a day for 5 days using the Germinator program (Joosen et al., 2010). For seedling stress assays, seeds were stratified at $4^{\circ} \mathrm{C}$ in the dark for $72 \mathrm{~h}$ on square $14-\mathrm{cm}$ Petri dishes on $1 / 2$ Murashige-Skoog (MS) medium supplemented with $0.5 \%$ sucrose, $0.1 \%$ MES monohydrate and 1\% Daishin agar, $\mathrm{pH} 5.8$ $(\mathrm{KOH})$. After 4 days, seedlings were transferred to the same medium supplemented with $100 \mathrm{mM} \mathrm{NaCl}$ or $200 \mathrm{mM}$ Mannitol. Each plate contained four seedlings of three genotypes, and three biological replicates per genotype were used following a complete randomized design. The plates were vertically placed at $21^{\circ} \mathrm{C}$ under continuous light. The primary root length was scored after 10 days. Drought stress was assessed by withholding water from 3-weekold A. thaliana plants grown on soil in the greenhouse. After 12 days, the percentage water content from the leaves was measured, and plants were rewatered. Final survival was analyzed 7 days after rewatering. Three biological replicates with three plants were used per time point. Leaves and soil fresh weight (FW) were measured immediately after harvest, and the dry weight (DW) was measured after $48 \mathrm{~h}$ at $60^{\circ} \mathrm{C}$. Percentage water content (\%) from the plants and soil was calculated as $(\mathrm{FW}-\mathrm{DW}) / \mathrm{FW} \times 100$.

\section{RESULTS}

\section{XsLEAs Are Predicted To Be Intrinsically Disordered}

The expression of the six XsLEAs used in our analysis has been reported by Costa et al. (2017) to be increased in $X$. schlechteri leaves upon desiccation between $60 \%$ RWC $\left(1.5 \mathrm{gH}_{2} \mathrm{O} \mathrm{g}^{-1} \mathrm{dwt}\right)$ and $40 \%$ RWC (1.0 $\mathrm{gH}_{2} \mathrm{O} \mathrm{g}^{-1} \mathrm{dwt}$ ) (Supplementary Figure 1), coinciding with the activation of the molecular signature of the resurrection physiology. In parallel, genes related to protein folding, protection and translational control were also enriched.

The cDNAs of the XsLEAs contained an open reading frame (CDS) ranging from 309 to 1149 nucleotides encoding proteins with 102 to 382 amino acids with molecular weights between 10.73 and $38.92 \mathrm{kDa}$ (Table 1). The theoretical pI ranged from

TABLE 1 | Characteristics of Xerophyta schlechteri late embryogenesis abundant (LEA) proteins.

\begin{tabular}{|c|c|c|c|c|c|c|c|}
\hline Gene ID* & PFAM & Name & CDS size & $\begin{array}{c}\text { Number of amino } \\
\text { acids }\end{array}$ & $\begin{array}{c}\text { Molecular weight } \\
\text { (kDA) }\end{array}$ & Theoretical pl & GRAVY \\
\hline Xvis02_06457 & pf04927 & XsSMP4 & 918 & 305 & 31.68 & 4.3 & -0.437 \\
\hline Xvis02_11331 & pf02987 & XsLEA4-8 & 441 & 146 & 15.55 & 6.6 & -1.316 \\
\hline Xvis02_12059 & pf02987 & XsLEA4-12 & 1149 & 382 & 38.92 & 5.9 & -0.872 \\
\hline Xvis02_20008 & pf03760 & XsLEA1-8 & 321 & 106 & 10.73 & 8.6 & -0.916 \\
\hline Xvis02_08790 & pf10714 & XsLEA6-2 & 309 & 102 & 11.11 & 5.0 & -1.095 \\
\hline Xvis02_23545 & pf00257 & XsDHN12 & 372 & 123 & 13.44 & 7.2 & -1.389 \\
\hline
\end{tabular}

${ }^{*}$ Gene IDs were retrieved from (Costa et al., 2017). 
4.3 to 8.6 , indicating that XsLEAs expressed upon desiccation constitute acidic, neutral, and basic proteins. All six XsLEAs had a negative GRAVY index, a common characteristic of hydrophilic LEA proteins (Battaglia et al., 2008).

The percentage of polar residues was relatively higher compared with non-polar residues in all XsLEAs, with the exception of XsSMP4 with 52.79\% non-polar residues (Supplementary Table 3). The disorder promoting amino acids alanine $(\mathrm{A})$, lysine $(\mathrm{K})$, glycine $(\mathrm{G})$, glutamine $(\mathrm{Q})$, and glutamic acid (E) were enriched in at least four of the six sequences. These characteristics indicate that the majority of the studied XsLEAs are likely to be IDPs (Dunker et al., 2001; Tompa, 2002). To verify the IDP properties of the XsLEAs, several in silico analyses were performed. All XsLEAs were predicted to belong to the category of proteins with extended disorderedness (Supplementary Figure 2A). With the exception of XsSMP4, all XsLEA protein sequences displayed high disorder tendency (Supplementary Figure 2B). XsSMP4 appeared to be the least disordered from the proteins herein investigated, because it displayed higher hydropathy and GRAVY (Table 1), as well as higher percentage of non-polar residues (Supplementary Table 3 ).

In silico structural analysis indicated that four proteins (XsLEA1-8, XsLEA4-8, XsLEA6-2, and XsDHN12) are predicted as Janus sequences, which are proteins that undergo environmentdependent conformational transitions (Supplementary Table 4). $\mathrm{XsSMP} 4$ is predicted to form tadpole and globular structures, in agreement with the less disordered nature of this protein. XsLEA4-12 is predicted to form coils, hairpins, and chimeras, representing a structurally more heterogeneous protein type. It is important to highlight that despite in silico analysis that allows the prediction of structural propensities in IDPs, these proteins exist as ensembles of conformations in natural conditions, which can be a balance between more ordered and disordered structures (Das et al., 2015).

DBRs are common among IDPs and may contain short fragments of about 5 to 25 residues named MoRFs that are prone to undergo disorder-to-order transitions in the presence of binding partners (Mohan et al., 2006). We found that the number of DBRs as well as the number of MoRFs was variable among the six XsLEAs and that the position of MoRFs not always correlated with those of DBRs (Supplementary Table 4, Supplementary Figure 3). XsDHN12 and XsLEA1-8 presented longer MoRFs within DBRs in the C-terminus, and XsLEA6-2 presented two longer MoRFs within DBRs located in the $\mathrm{N}$ and C-terminus. Interestingly, the three proteins presenting larger number of smaller DBRs (XsLEA4-8, XsLEA4-12, and XsSMP4), also presented no or smaller MoRFs within DBRs (Supplementary Figure 3). These observations indicate that there is a high variability regarding the number, size, and locations of DBRs and MoRFs between the different XsLEA proteins and suggest that XsDHN12, XsLEA1-8, and XsLEA6-2 may undergo higher conformational changes in the presence of binding partners.

The binding affinity of MoRFs is believed to be modulated by phosphorylation of MoRF residues (Mohan et al., 2006). We investigated the percentage and location of phosphorylation residues (Ser, Thr, and Tyr) of the six XsLEAs (Supplementary
Figure 3, Supplementary Table 4). The percentage of predicted phosphorylation sites was variable between the six LEA proteins, with XsLEA4-12 showing the highest percentage (20.7\%) followed by XsLEA4-8 (13.2\%). Interestingly, in most of the proteins analyzed, the predicted phosphorylation sites were located outside the MoRF regions (Supplementary Figure 3) suggesting that phosphorylation may not be the major modulator of binding affinity in XsLEAs via MoRF recognition, although further experimental data are still needed to confirm this in silico observation.

\section{XsLEAs Are Intrinsically Disordered in Aqueous Solution and Display Conformational Plasticity}

His-tagged recombinant XsLEAs were produced to investigate their structure in solution. Similar to other LEA proteins (Kovacs et al., 2008; Hundertmark et al., 2011), all the XsLEAs showed slightly higher molecular masses in an SDS gel than the predicted mass (Table 1, Supplementary Figure 4). This lower gel mobility might be due to the $6 \mathrm{xHis}$-tag or due to the hydrophilic character of IDPs (Tompa, 2002; Kovacs et al., 2008). All XsLEAs used in our analysis were confirmed to be heat stable, a common characteristic of LEA proteins, which are known to be a part of the heat-stable proteome associated with DT in seeds (Boudet et al., 2006; Kovacs et al., 2008; Chatelain et al., 2012).

We investigated the disordered nature and folding behavior of the six XsLEAs in aqueous solution by CD spectroscopy. BSA was used as a positive control protein due to its predominantly a-helical conformation (Reed et al., 1975). This is reflected in the BSA spectra, which characterized by a positive maximum at $\sim 190 \mathrm{~nm}$ and negative minimum at $208 \mathrm{~nm}$ and $220 \mathrm{~nm}$ (Supplementary Figure 5A). In general, the spectra of the six analyzed XsLEAs were characterized by a negative minimum between 198 and $201 \mathrm{~nm}$ in water (Supplementary Figures 5B-G), which is characteristic of natively unfolded proteins (Uversky, 2009; Lopes et al., 2014). A residual alpha-helix content was commonly observed in all XsLEAs in aqueous solution, and the presence of turns or strands was variable between the six proteins (Supplementary Figure 5H). Taken together, these results confirm that the six investigated XsLEAs are proteins with intrinsically disordered regions (IDRs).

To test the effect of changes in the $\mathrm{pH}$ and composition of the solvent we analyzed the spectra of the six XsLEAs in aqueous solutions adjusted with $\mathrm{HCl}$ to $\mathrm{pH} 4.0$ or $\mathrm{pH} 2.3$, and in the presence of $20 \mathrm{mM} \mathrm{NaCl}$ or $80 \%$ ACN. The decrease in the $\mathrm{pH}$ or addition of $20 \mathrm{mM}$ of $\mathrm{NaCl}$ did not significantly affect the spectra of BSA when compared to aqueous solution and had little effect on the secondary structure content of XsLEAs (Supplementary Figures 5A-H). The most noticeable secondary structure variations in these conditions were observed for XsLEA1-8, with an increase in helix content at $\mathrm{pH}$ 2.3, and for XsLEA4-8, with an increased strand formation in $\mathrm{NaCl}$ solution (Supplementary Figure $\mathbf{5 H}$ ). On the other hand, high concentrations of the organic solvent ACN resulted in considerable changes in the secondary structure of XsLEAs (Figures 1A-F). ACN is an organic water miscible 
solvent that can increase protein chemical potential leading to conformational changes, acting as a denaturant, as well as an alpha-helix-promoting agent (Gekko et al., 1998). With the exception of XsLEA4-12, a decrease of the negative minima (between 197 and $200 \mathrm{~nm}$ ) converting it to a positive signal and an increased negative signal between 210 and $240 \mathrm{~nm}$ was commonly observed in the spectra of all XsLEAs in $80 \%$ ACN solution, resulting in a reduction of unordered regions (Figure 1H).

The protein XsLEA4-12 showed atypical behavior in $80 \%$ ACN, with increased negative signal around 195 and $200 \mathrm{~nm}$, and a positive signal near $230 \mathrm{~nm}$. The spectrum of this protein between 195 and $220 \mathrm{~nm}$ resembles that of a denatured or aggregated protein (Venyaminov et al., 1993; Greenfield, 2006). Different from what was observed for XsLEAs, BSA showed a decrease in helix content and appearance of disordered, turns and strand conformations in $80 \%$ ACN (Figures 1G, H). Interestingly, XsLEA1-8 underwent a conformational change from about $92 \%$ disordered in aqueous solution up to $100 \%$ alpha-helix in $80 \%$ ACN (Figure 1H). In summary, our results suggest that XsDHN12, XsLEA1-8, XsLEA4-8, XsLEA6-2, and XsSMP4 display conformational plasticity and underscore the plasticity of XsLEA1-8 to acquire high degrees of secondary structure in a highly hydrophobic environment.

\section{XsLEAs Stabilize Enzyme Activity Upon Stress in a Protein-Specific Manner}

We investigated the in vitro protective functions of the different XsLEAs on the activity of the enzyme LDH during desiccation, heat and oxidative stress (Figure 2).

Under desiccation, we observed a reduction of $\mathrm{LDH}$ activity to about $15 \%$ of control levels. With the exception of XsLEA4-12, all XsLEAs showed protective functionality against desiccation on the activity of $\mathrm{LDH}$, with a protection of enzymatic activity up to $63 \%$ with XsLEA1-8. We found that heat stress reduced LDH activity to about $27 \%$ in the absence of XsLEAs, and XsLEA4-12 was unable to protect LDH activity. However, all other XsLEA proteins were able to protect LDH activity against heat, and again XsLEA1-8 showed the highest protective ability. The heat-protection activity of isolated LEA proteins has already been demonstrated in in vitro assays before (Goyal et al., 2005b; Kovacs et al., 2008; Halder et al., 2017), indicating that thermal anti-aggregation is a common feature of several LEA proteins.

The oxidative treatment imposed by $\mathrm{H}_{2} \mathrm{O}_{2}$ was less stressful as compared to desiccation and heat treatments. $\mathrm{LDH}$ activity dropped to $56 \%$ when treated with $\mathrm{H}_{2} \mathrm{O}_{2}$ and, with the exception of XsLEA4-12, all proteins tested were able to protect enzyme activity. Taken together, these results suggest that XsDHN12, XsLEA1-8, XsLEA4-8, XsLEA6-2, and XsSMP4 have
A

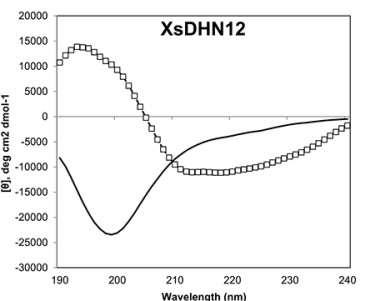

D

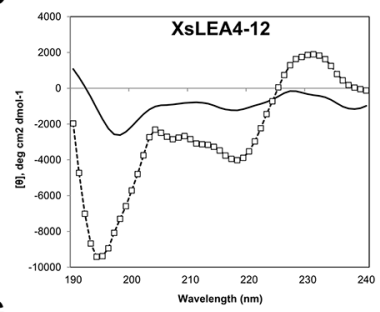

G

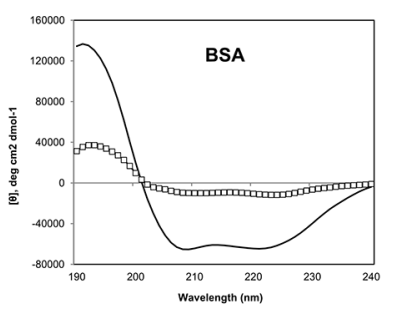

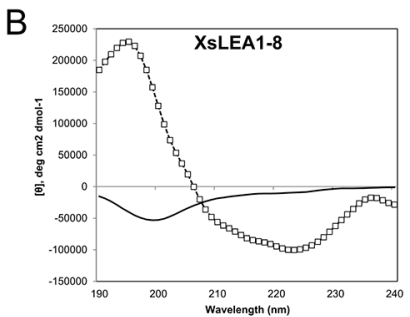

E

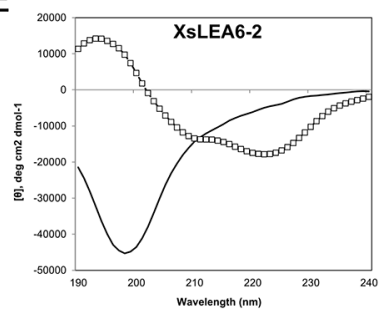

$\mathrm{H}$

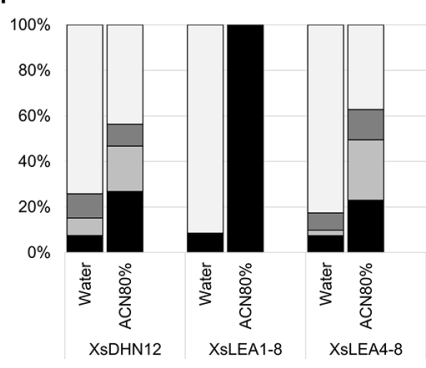

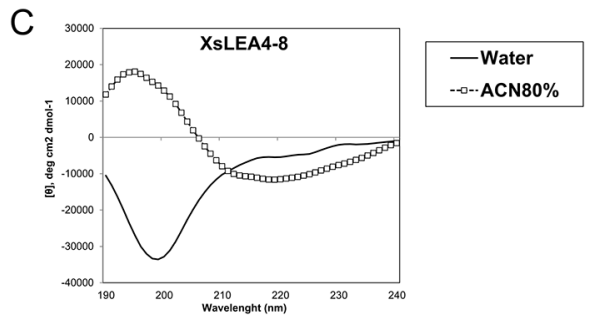

F
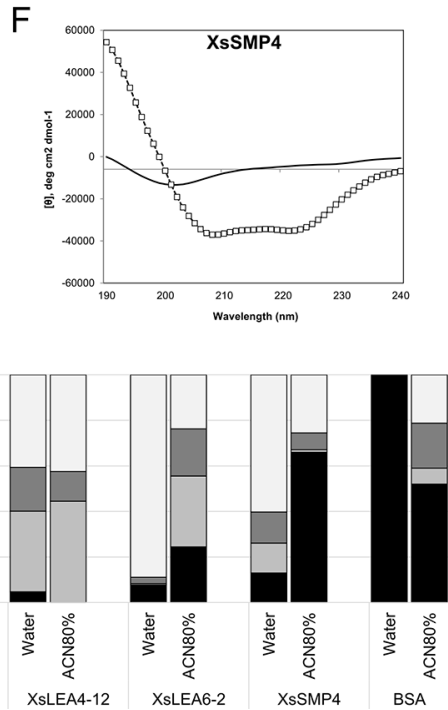

FIGURE 1 | Normalized CD spectra of Xerophyta schlechteri late embryogenesis abundant (LEA) proteins and bovine serum albumin (BSA). The CD spectra were obtained in water and $80 \%$ acetonitrile (ACN). All the spectra were analyzed at room temperature (A-G). The graphs show the spectra obtained after subtracting the reads of a blank sample containing water only. $(\mathbf{H})$ Secondary structure content of $X$. schlechteri LEAs (XsLEAs). Analyses of the CD data to obtain an estimation of the content of helix, strand, turns and unordered conformations were performed with Dichroweb. 


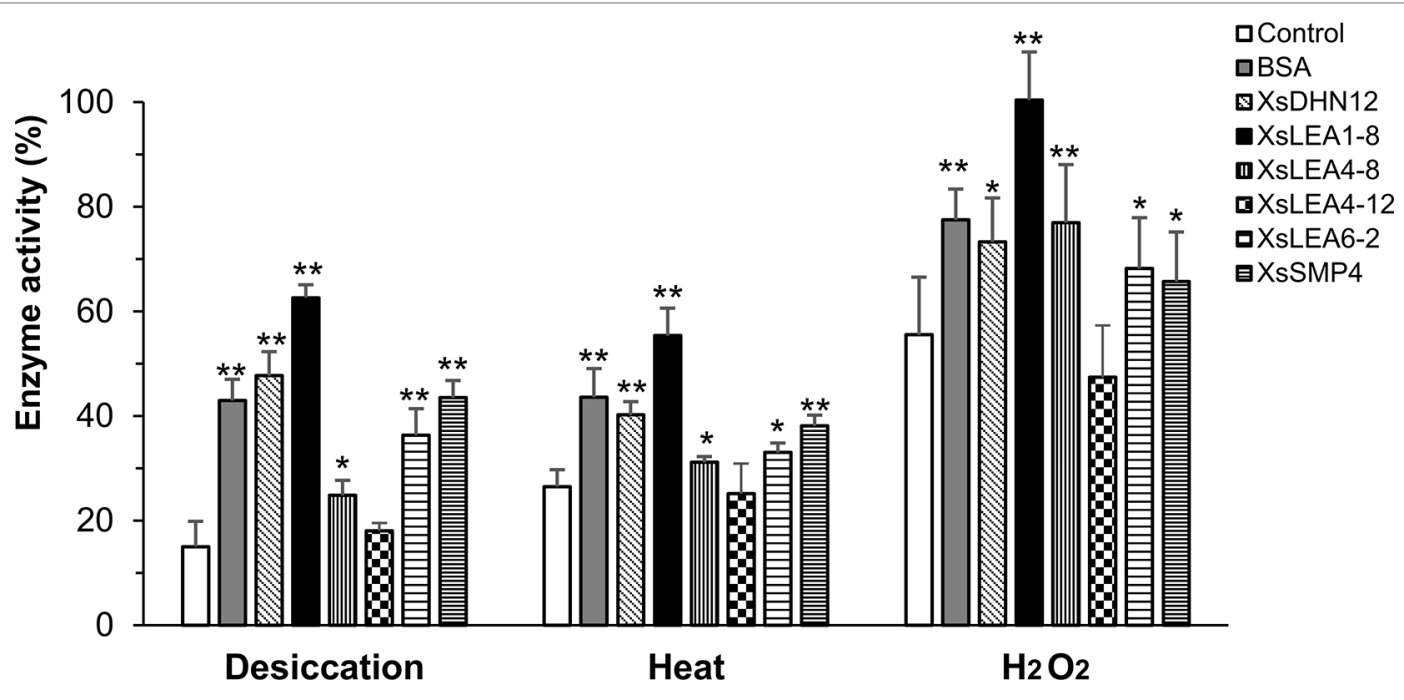

FIGURE 2 | Protective function of $X$. schlechteri LEAs (XsLEAs) on lactate dehydrogenase (LDH) activity under stressful conditions. LDH by itself (negative control) or in the presence of one of the six purified XsLEAs or bovine serum albumin (BSA) (positive control) at a molar ratio of 1:1 were used to assess effects of desiccation, heat and oxidative stress. The experiments were repeated three times with three technical replicates in each experiment. Statistically significant differences as compared to control were analyzed using Student's $t$-test $\left({ }^{\star} p<0.05\right.$ or $\left.{ }^{* *} p<0.01\right)$. The error-bars represent SD from nine replicates $(n=9)$.

chaperone-like activities for LDH activity upon desiccation, heat and oxidative stress, and that XsLEA4-12 is ineffective in the conditions herein tested.

\section{In Vivo Expression Of XsLEAs Enhances E. coli Viability Under Salt, Osmotic And Heat Stress}

To investigate effects of XsLEA expression on E. coli survival, we analyzed colony growth on plates with high concentrations of $\mathrm{NaCl}$ and mannitol, or when subjected to a heat shock (Figure 3A).

Under control conditions, the strain expressing XsLEA6-2 displayed decreased growth than the empty vector-carrying strain, while the strain expressing XsLEA1-8 displayed significant better growth than all other strains (data not shown). Interestingly, the XsLEA1-8 strain also displayed better growth in all stressful conditions, suggesting that this protein has a higher protective function in $E$. coli when compared to the other tested XsLEAs. The strain with XsLEA6-2 and XsDHN12 presented a slower colony growth in all tested stresses, and, after heat treatment, the strain expressing XsSMP4 also presented slower growth compared with the empty vector. These results show that not all XsLEAs have a protective function during $E$. coli growth under the tested conditions.

When analyzing relative growth of the strains in liquid media with a lower concentration of $\mathrm{NaCl}$, we observed that after $6 \mathrm{~h}$, all strains expressing XsLEAs displayed better growth than the empty vector (Figure 3B). Once more, the bacterial cells expressing XsLEA1-8 showed a remarkable better growth recovery at the end of the experiment, indicating that this protein may perform a better protective function of $E$. coli upon salt stress as compared to the other tested XsLEAs. Interestingly, in the first $4 \mathrm{~h}$ of stress, a few strains displayed slower growth when compared to the empty vector. This observation might be due to leakiness of the expression vector, because the activation of the T7 promoter during bacterial growth prior induction will lead to production of recombinant protein which may limit bacterial growth (Grossman et al., 1998; Zhang et al., 2015; Briand et al., 2016). It is possible that the production of some XsLEAs during bacterial growth prior to the stress treatments might have detrimental effects on growth, likely due to unspecific binding to other molecules, furthermore, variations in the time and levels of protein produced in the different strains may interfere with the results observed. Taken together, our results point toward a potential protective role of XsLEA1-8 in vivo.

\section{Multiple Localizations of XsLEAs in Plant Cells}

LEA proteins can be localized in various cell compartments, including the nucleus, cytosol, plasma membrane, mitochondria, plastids, endoplasmic reticulum (ER), and vacuoles (Hundertmark and Hincha, 2008; Candat et al., 2014). Prediction of subcellular localization indicates that XsDHN12, XsLEA1-8, XsLEA6-2, and XsSMP4 localize mainly in the nucleus and cytoplasm (Supplementary Table 5). The nuclear and cytoplasmic localization of proteins from families DHN, LEA_1, LEA_6, and SMP have been shown in vivo for A. thaliana (Candat et al., 2014), indicating that in silico analysis may have a strong correlation with in vivo analysis for these LEA families. XsLEA4-8 was predicted to be localized in the cytoplasm, nucleus, cell wall and plastids, and XsLEA4-12 in the nucleus, cytoplasm, and cell wall, corroborating the experimental data of multilocalization of A. thaliana LEA_4 proteins (Candat et al., 2014). Despite limitations of in silico predictions, these tools seem to be useful to design experiments for studying in vivo subcellular localization of LEA proteins. 


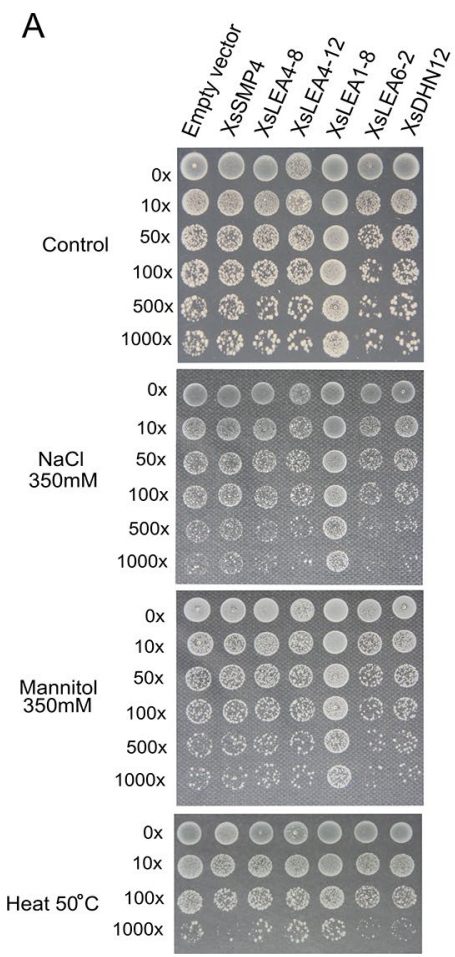

B

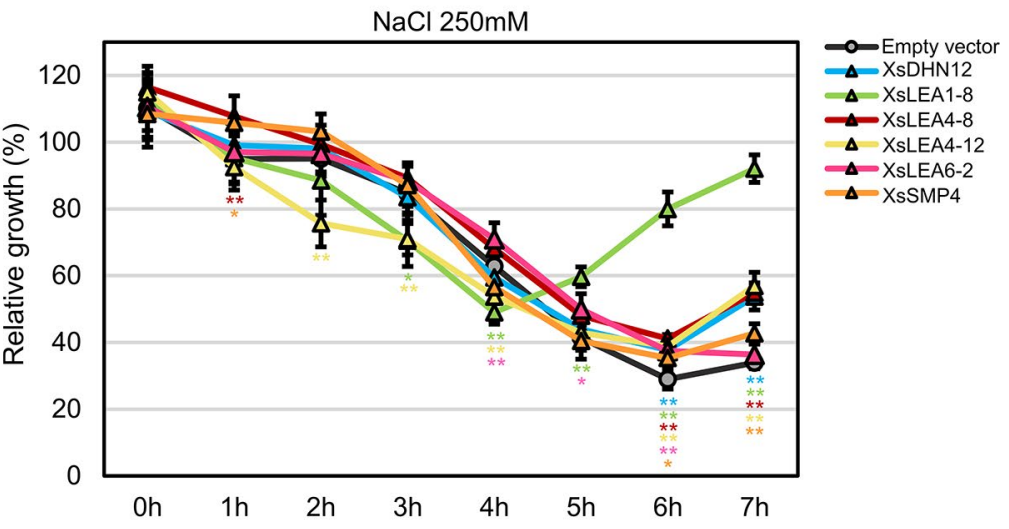

FIGURE 3 | In vivo protective role of XsLEAs. (A) Response to salt, osmotic and heat stresses. (B) Relative growth of E. coli in liquid media with 250 mM NaCl. The experiments were repeated twice with three replicates per construct. Statistically significant differences were analyzed using Student's $t$-test, and the bars indicates SD $\left({ }^{\star} p<0.05\right.$ or $\left.{ }^{\star *} p<0.01\right)$.

To verify the in vivo subcellular localization of XsLEAs and to compare in vivo and in silico analysis, we expressed GFP fusions of XsLEA proteins in tobacco leaf epidermal cells under control of a $35 \mathrm{~S}$ promotor (Supplementary Figure 6). The GFP-XsLEA proteins were localized throughout the cell compartments, especially in the cytoplasm, nucleus and membranes. GFPXsLEA1-8, GFP-XsLEA4-8, and GFP-XsLEA6-2 accumulated mainly in the cytoplasm, membranes and nucleus, in the same way as the GFP empty vector. GFP-XsLEA4-12 showed a signal around the cells and in aggregate-like structures inside the cells which suggest that this protein may be secreted. GFP-XsSMP4 and GFP-XsDHN12 accumulated mainly in the membranes, and GFP-XsDHN12 also in the nucleus. In summary, our results indicate that the six $X$. schlechteri LEA proteins involved in DT in leaves are heterogeneously localized throughout various subcellular compartments. Further analyses combining C-terminal fusions and organelle specific markers are necessary to draw stronger conclusions on the specific localization of each of these proteins and further hypothesize about their cellular role.

\section{Heterologous Expression of XsLEA1-8 Enhances A. thaliana Stress Tolerance}

A. thaliana ecotype Columbia-0 plants were transformed with a 35S::XsLEA1-8 construct, which led to a constitutive expression of the XsLEA1-8 gene, including in the dry seed (Supplementary
Figure 7). The phenotypic analysis of seeds expressing the $35 S:: X s L E A 1-8$ indicated that the germination percentages of WT and five independent lines did not differ significantly under control conditions (Supplementary Figure 8). During germination under salt, osmotic, and heat shock stress, a mild protective response was observed in two independent lines, indicating that XsLEA1-8 may not play a significant role in seed germination under the conditions tested here.

We also investigated the growth ability of seedlings of $35 S:: X s L E A 1-8$ in media containing salt and mannitol (Figure 4). Under salt stress, the independent lines XsLEA1-8.4 and XsLEA1-8.8 displayed longer primary roots. Under osmotic stress imposed by mannitol, three independent lines $(4,6$, and 7 ) displayed longer primary roots when compared with the wildtype. The phenotypic analysis of transgenic A. thaliana adult plants under drought stress showed that three independent lines $(3,7$, and 8$)$ displayed significantly higher relative water content at 12 days after withholding water (Supplementary Figure 9A); however, at this time point, no significant difference was observed in the DW of the transgenic lines when compared to the wildtype (Supplementary Figure 9B). These results suggest that the transgenic lines expressing XsLEA1-8 may display a better control of water loss during drying, which may enhance their survival (Supplementary Figure 9C). Together, these findings point toward a potential role of XsLEA1-8 in enhancing osmotic stress tolerance in plants. 
A
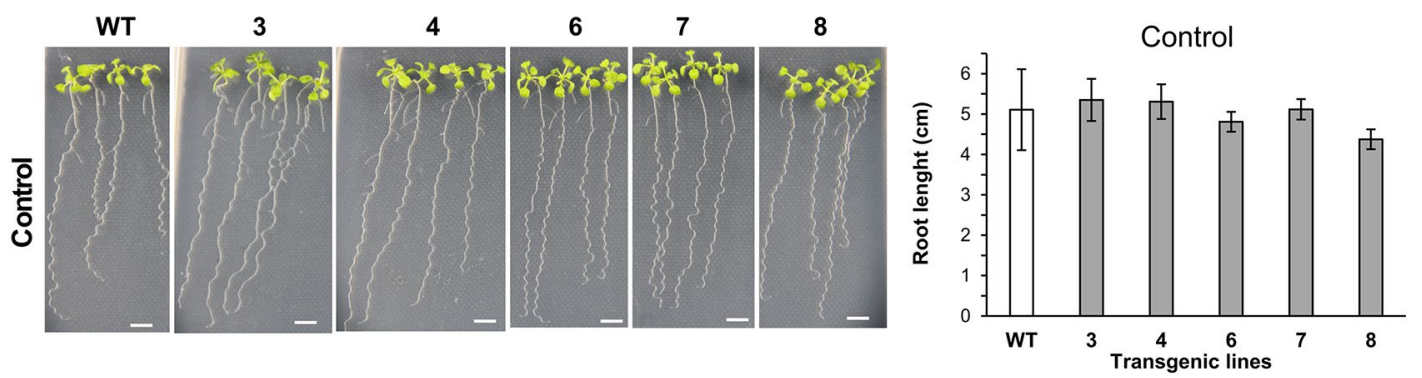

B
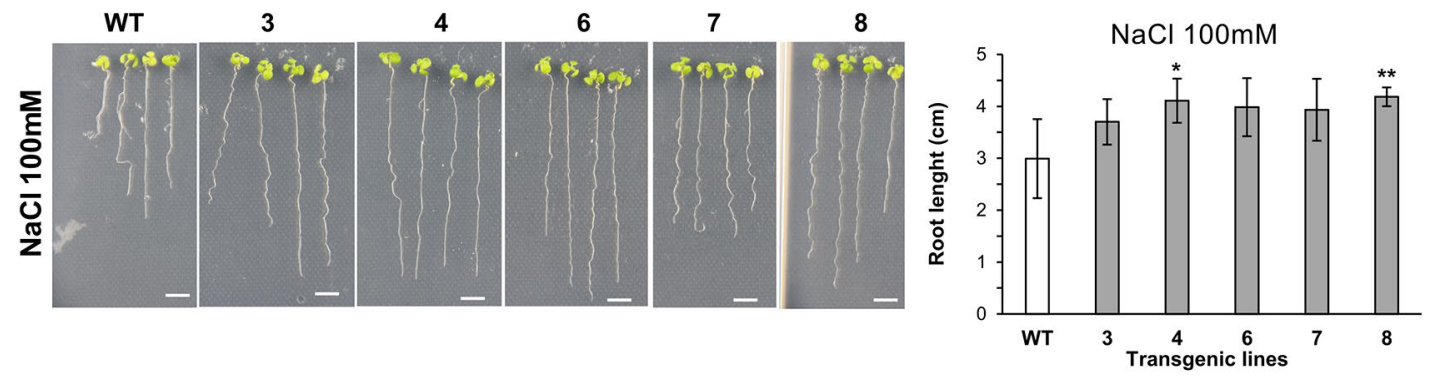

C
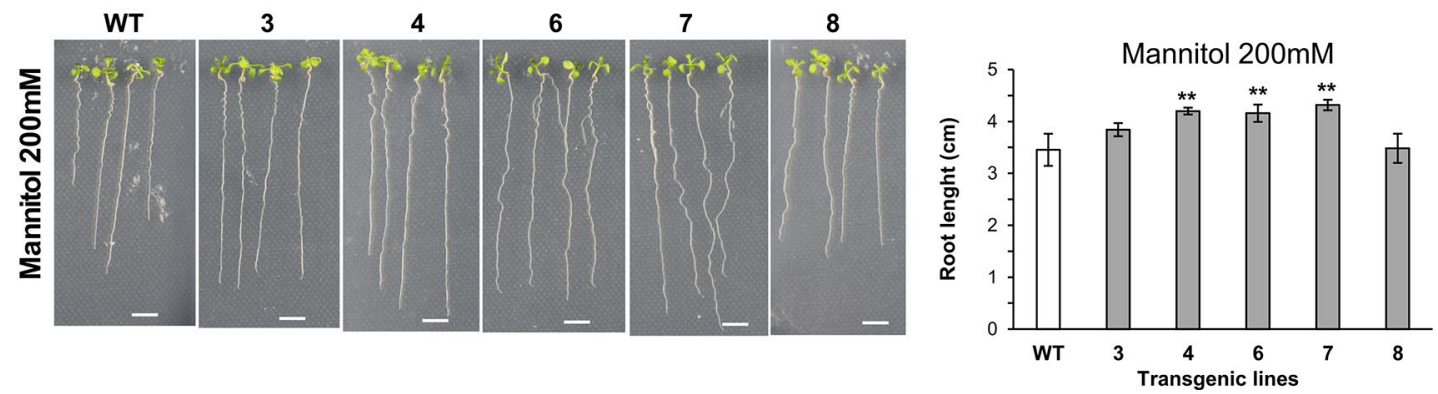

FIGURE 4 | Phenotypic analysis of $A$. thaliana seedlings expressing XSLEA1-8. Seedlings grown on plates under control conditions (A), $100 \mathrm{mM}$ NaCl (B), and $200 \mathrm{mM}$ mannitol $\mathbf{( C )}$ are shown at the left. Data of one representative experiment are shown. Bars showing average root length \pm SD ( $n=3)$ are shown at the right. Statistically significant differences between the transgenic lines and the wild type (WT) were tested using Student's $t$-test $\left({ }^{*} p<0.05\right.$ or $\left.{ }^{\star \star} p<0.01\right)$. Scale bars $=0.5 \mathrm{~cm}$.

\section{DISCUSSION}

Since their discovery as accumulating during the later stages of seed embryogenesis, increasing evidence suggests a protective function of LEA proteins against desiccation and other stresses, leading to great interest in the structural dynamics of these proteins in the subcellular environment. As in seeds, LEA proteins have been shown to be an essential footprint of vegetative DT in resurrection plants. $X$. schlechteri is a monocot resurrection species whose genome has recently become available, enabling comparative genomic analysis with other monocots and resurrection species, as well as the understanding of the evolution and functional diversification of LEA proteins and their role in these organisms (Costa et al., 2017; Artur et al., 2018). LEA gene expression is upregulated in leaves of $X$. schlechteri between $60 \%$ and 40\% RWC (1.5-1.0 gW/gDW) (Supplementary Figure 1), concomitant with the activation of the molecular signature of DT in seeds and resurrection plants (Illing et al., 2005; Leprince and Buitink, 2010; Costa et al., 2017).

In silico analysis of six $X$. schlechteri LEA proteins upregulated during desiccation indicated that these are typical IDPs, as they have IDRs in water, and properties, such as a high percentage of polar residues, low GRAVY scores, and extended disordered regions (Artur, 2019; Dunker et al., 2001; Tompa, 2002; Battaglia et al., 2008). Predictions of biochemical properties may give insight into the lack of structure of a protein. However, it is important to highlight that isolated parameters, such as length of polypeptide, net charge, or pI, cannot be used as a signature of unfolded or disordered structure (Uversky et al., 2000), revealing the necessity for more extensive in silico analysis to better predict the structural nature of such proteins. Using a specific predictor for Classification of Intrinsically Disordered Ensemble Regions (CIDER) (Holehouse et al., 2017), we found that XsLEAs belong to different IDP categories, such as environmentally determined disordered, globular, coiled, and chimeras of globular and coiled proteins. Two XsLEAs (XsSMP4 and XsLEA4-12) were predicted to contain structured regions, which is also a common feature of some IDPs able to form globules or chimeras of globules and coils and are able to undergo folding upon binding (Dyson and Wright, 2002; Dyson and Wright, 2005; Das et al., 2015). In fact, IDPs are able to interact with other molecules via Molecular Recognition Features (MoRFs) that undergo disorder-to-order transitions 
in the presence of binding partners (Mohan et al., 2006). We found that MoRFs are present in a low number within XsLEA sequences and, in general, they localize within predicted DBRs of the XsLEAs. MoRFs are thought to play important functions in protein-protein interactions related to signaling (Oldfield et al., 2005; Mohan et al., 2006; Disfani et al., 2012). In this way, the investigation of mutations of specific amino acids contributing to MoRFs will provide further insights into the specific role of these regions as well as interactions of LEA proteins with other proteins.

Reversible phosphorylation of IDPs is one of the major PTMs responsible for functional regulation of binding affinity of MoRFs (Iakoucheva et al., 2004; Mohan et al., 2006) and has already been shown to affect the function of LEA proteins in plants (Heyen et al., 2002; Alsheikh et al., 2003; Alsheikh et al., 2005; Brini et al., 2007; Liu et al., 2017). In silico analysis indicated that all the six XsLEAs have phosphorylation sites, with a remarkable high number in XsLEA4-12. However, in general, we found that the phosphorylation residues did not coincide with the predicted MoRF contributing residues, what suggests that phosphorylation may not play an important role in regulating binding affinity of MoRFs in the studied proteins.

In this study, we also investigated the in vitro folding dynamics of the six XsLEAs using circular dichroism (CD). Conformational changes of IDPs in vitro can be induced by changes in their environment such as $\mathrm{pH}$, temperature, and presence of osmolytes or binding targets (Uversky, 2002; Uversky, 2009). Several studies have shown that LEA proteins are mainly disordered in aqueous solutions and are able to acquire secondary structures, mainly alpha-helices, upon desiccation and solute perturbations (Mouillon et al., 2006; Shih et al., 2010; Popova et al., 2011; Hundertmark et al., 2012; Shih et al., 2012; Cuevas-Velazquez et al., 2016). Our CD spectra corroborate the in silico predictions of the disordered (or unstructured) nature of the XsLEAs in aqueous solution (Figure 1). XsLEAs also possess residual structured regions which is also commonly found in IDPs (Tompa, 2012). Similar characteristics can be found in polypeptides containing local order, such as helix and beta-sheet like structures, and, in these proteins, secondary structure can be induced by variations in temperature, $\mathrm{pH}$, presence of binding targets, osmolytes, and variable solvent concentrations (Shi et al., 2002; Soulages et al., 2002; Uversky, 2009; Rivera-Najera et al., 2014; CuevasVelazquez et al., 2016; Bremer et al., 2017). In fact, we observed that XsLEAs are able to acquire higher degrees of secondary structure in a hydrophobic solution of ACN. A highlight was the protein XsLEA1-8, which became fully alpha-helical in a solution of $80 \%$ ACN. ACN-mediated folding is triggered by significant reduction of hydration layers in direct contact with the protein surface, leading to conformational changes, such as formation of helices and sheets (Nelson et al., 1997; Gekko et al., 1998; Simon et al., 2001). This finding indicates that, under highly hydrophobic conditions, XsLEA proteins may acquire secondary structure, which may also be a factor regulating their functional activity.

It has already been shown that IDPs are able to preserve enzyme activity and avoid protein aggregation upon cellular stress by the ability to vitrify and trap cellular macromolecules into an amorphous matrix avoiding aggregation (Chakrabortee et al., 2007; Boothby et al., 2017). Several LEA proteins have been shown to protect enzymes from thermal and chemical inactivation and aggregation in vitro (Goyal et al., 2005a; Nakayama et al., 2007; Kovacs et al., 2008; Furuki and Sakurai, 2016; Liu et al., 2016; Agarwal et al., 2017; Halder et al., 2017). We investigated the ability to undergo conformational changes and acquire higher secondary structure under stress and the protective ability of XsLEAs. With the exception of XsLEA4-12, all studied proteins were able to preserve enzymatic activity upon desiccation, heat and oxidative stress in vitro, which supports the hypothesis that the high conformational changing ability correlates with protective abilities against aggregation and denaturation. It is important to highlight that since we undertook these experiments, new information on more reliable methods for IDPs quantification became available (Contreras Martos et al., 2018). As IDPs may show extreme variations in amino acid composition and physical properties, the use of more accurate quantification methods, such as ninhydrin and Qubit in combination with an absolute method, is recommended to draw more reliable conclusions about their structure. In vivo assays using E. coli have successfully demonstrated the protective role of LEA proteins upon stress (Zhang et al., 2014; Drira et al., 2015; Gao and Lan, 2016; Hu et al., 2016; Ling et al., 2016; Liu et al., 2016; Shi et al., 2016; Boothby et al., 2017; Jiang et al., 2017; Rakhra et al., 2017; Saucedo et al., 2017; Wang et al., 2017; Zhou et al., 2017). We found that several XsLEAs are able to improve bacterial growth under salt and osmotic stress, and the strains expressing XsLEA1-8 presented a faster stress recovery. Combined, these results indicate a correlation between in vitro and in vivo protective functions and point toward a potential application of the properties of XsLEA1-8 for engineering stability in vitro and in vivo.

Subcellular localization analysis assists in inferring function of proteins in plants. A. thaliana members of DHN, LEA_1, LEA_6, and SMP were shown to localize predominantly in the nucleus and cytoplasm, while LEA_4 members were multilocalized across chloroplasts, mitochondria, ER and pexophagosomes (Candat et al., 2014). In silico analysis of the six XsLEAs investigated in this study confirms the expected nucleo-cytoplasmic localization of XsDHN12, XsLEA1-8, XsLEA6-2, and XsSMP4, while XsLEA4-8 and XsLEA4-12 were predicted to also localize to the plastids and cell wall. In some cases, in silico and in vivo analysis may result in different results, as the example of an AdLEA protein from wild peanut, of which in silico analysis indicated localization mainly in the cytoplasm, while the GFP-fused protein was localized in the nucleus and cytoplasm (Sharma et al., 2016). In our in vivo analysis using GFP-fusions, subcellular locations of most XsLEAs were similar to the in silico predictions, showing that the latter can be useful for preliminary characterization of subcellular localization. To investigate the transferability of the protective properties shown by in vitro and in vivo assays in bacteria into enhancing plant stress tolerance, we developed transgenic $A$. thaliana plants constitutively expressing the XsLEA1-8 gene. The expression of XsLEA1-8 did not enhance stress tolerance during seed germination, but was able to enhance primary root growth under salt and osmotic stress in seedlings. Transgenic adult plants expressing XsLEA1-8 displayed a higher absolute water content after 12 days of drought, indicating that this gene may play a role in plant drought tolerance.

Our study provides evidence for the structure-function relationship of LEA proteins expressed during desiccation in 
$X$. schlechteri plants. Our data reveal that in silico and in vitro analysis can provide useful information about LEA protein functions. We hypothesize that XsLEAs have been evolutionarily selected to be able to adopt diversified conformations driven by variations in their cellular environment. The conformational plasticity and multilocalization of XsLEAs may enable binding to essential cellular components (such as enzymes) and regulation of loss of water from cells, resulting in enhanced osmotic stress tolerance in $X$. schlechteri leaf cells. Furthermore, we believe that the high conformational plasticity and protective abilities of XsLEA1-8 make it a potential candidate for engineering biostability in vitro by serving as a model for synthetic chaperons, as well as for enhancing drought tolerance in crop species.

\section{DATA AVAILABILITY STATEMENT}

All datasets generated for this study are included in the manuscript/Supplementary Files.

\section{AUTHOR CONTRIBUTIONS}

MA performed the in silico analysis and data interpretation. MA and JR performed gene cloning for bacterial assays. JR performedgene cloning for plant heterologous expression. MA: MA performed the in vitro assays and data analysis with significant contribution of TD. HH, WL and JF participated in the design of the study and

\section{REFERENCES}

Agarwal, T., Upadhyaya, G., Halder, T., Mukherjee, A., Majumder, A. L., and Ray, S. (2017). Different dehydrins perform separate functions in Physcomitrella patens. Planta 245, 101-118. doi: 10.1007/s00425-016-2596-1

Alsheikh, M. K., Heyen, B. J., and Randall, S. K. (2003). Ion binding properties of the dehydrin ERD14 are dependent upon phosphorylation. J. Biol. Chem. 278, 40882-40889. doi: 10.1074/jbc.M307151200

Alsheikh, M. K., Svensson, J. T., and Randall, S. K. (2005). Phosphorylation regulated ion-binding is a property shared by the acidic subclass dehydrins. Plant Cell Environ. 28, 1114-1122. doi: 10.1111/j.1365-3040.2005.01348.x

Artur, M. A. S., Zhao, T., Ligterink, W., Schranz, E., and Hilhorst, H. W. (2018). Dissecting the genomic diversification of LATE EMBRYOGENESIS ABUNDANT (LEA) protein gene families in plants. Genome Biol. Evol. 11, 459-471. doi: 10.1093/gbe/evy248

Artur, M. A. S. (2019). Unfolding plant desiccation tolerance: evolution, structure, and function of LEA proteins. PhD thesis. The Netherlands: Wageningen University.

Battaglia, M., Olvera-Carrillo, Y., Garciarrubio, A., Campos, F., and Covarrubias, A. A. (2008). The enigmatic LEA proteins and other hydrophilins. Plant Physiol. 148, 6-24. doi: 10.1104/pp.108.120725

Behnke, H.-D., Hummel, E., Hillmer, S., Sauer-Gürth, H., Gonzalez, J., and Wink, M. (2013). A revision of African Velloziaceae based on leaf anatomy characters and rbcL nucleotide sequences. Bot. J. Linn. Soc. 172, 22-94. doi: 10.1111/boj.12018

Bewley, J. D. (1995). Physiological-aspects of desiccation tolerance-a retrospect. Int. J. Plant Sci. 156, 393-403. doi: 10.1086/297261

Boothby, T. C., Tapia, H., Brozena, A. H., Piszkiewicz, S., Smith, A. E., Giovannini, I., et al. (2017). Tardigrades use intrinsically disordered proteins to survive desiccation. Mol. Cell 65, 975-984. doi: 10.1016/j.molcel.2017.02.018

Boudet, J., Buitink, J., Hoekstra, F. A., Rogniaux, H., Larre, C., Satour, P., et al. (2006). Comparative analysis of the heat stable proteome of radicles of Medicago truncatula seeds during germination identifies late embryogenesis supervised the project. MA wrote the manuscript. All authors contributed with comments and revision of the manuscript.

\section{FUNDING}

MA received financial support from CAPES-Brazilian Federal Agency for Support and Evaluation of Graduate Education (BEX 0857/14-9). Conformation analyses and enzyme protection assays were funded by a DST-NRF South African Research Chair grant (number 98406) awarded to JF.

\section{ACKNOWLEDGMENTS}

The authors thank Esmer Jongedijk (Wageningen University) for providing the pCDF-Duet empty vector, Jeanne Korsmann (University of Cape Town) for providing competent cells of BL21 (DE3) pLysS, Mahdu Chauan (University of Cape Town) for technical assistance with the CD-spectra analysis, and Dr. Eric Limpens (Wageningen University) for technical support with the confocal microscopy. The data presented in this manuscript are part of the PhD thesis of Artur (2019).

\section{SUPPLEMENTARY MATERIAL}

The Supplementary Material for this article can be found online at: https://www.frontiersin.org/articles/10.3389/fpls.2019.01272/ full\#supplementary-material abundant proteins associated with desiccation tolerance. Plant Physiol. 140 1418-1436. doi: 10.1104/pp.105.074039

Bremer, A., Wolff, M., Thalhammer, A., and Hincha, D. K. (2017). Folding of intrinsically disordered plant LEA proteins is driven by glycerol-induced crowding and the presence of membranes. FEBS J. 284, 919-936. doi: 10.1111/febs.14023

Briand, L., Marcion, G., Kriznik, A., Heydel, J.-M., Artur, Y., Garrido, C., et al. (2016). A self-inducible heterologous protein expression system in Escherichia coli. Sci. Rep. 6, 33037. doi: 10.1038/srep33037

Brini, F., Hanin, M., Lumbreras, V., Irar, S., Pages, M., and Masmoudi, K. (2007). Functional characterization of DHN-5, a dehydrin showing a differential phosphorylation pattern in two Tunisian durum wheat (Triticum durum Desf.) varieties with marked differences in salt and drought tolerance. Plant Sci. 172, 20-28. doi: 10.1016/j.plantsci.2006.07.011

Buitink, J., and Leprince, O. (2004). Glass formation in plant anhydrobiotes: survival in the dry state. Cryobiology 48, 215-228. doi: 10.1016/j.cryobiol.2004.02.011

Candat, A., Paszkiewicz, G., Neveu, M., Gautier, R., Logan, D. C., AvelangeMacherel, M. H., et al. (2014). The ubiquitous distribution of late embryogenesis abundant proteins across cell compartments in Arabidopsis offers tailored protection against abiotic stress. Plant Cell 26, 3148-3166. doi: 10.1105/ tpc. 114.127316

Chakrabortee, S., Boschetti, C., Walton, L. J., Sarkar, S., Rubinsztein, D. C., and Tunnacliffe, A. (2007). Hydrophilic protein associated with desiccation tolerance exhibits broad protein stabilization function. Proc. Nat. Acad. Sci. U. S. A. 104, 18073-18078. doi: 10.1073/pnas.0706964104

Chatelain, E., Hundertmark, M., Leprince, O., Le Gall, S., Satour, P., DelignyPenninck, S., et al. (2012). Temporal profiling of the heat-stable proteome during late maturation of Medicago truncatula seeds identifies a restricted subset of late embryogenesis abundant proteins associated with longevity. Plant Cell Environ. 35, 1440-1455. doi: 10.1111/j.1365-3040.2012.02501.x

Clough, S. J., and Bent, A. F. (1998). Floral dip: a simplified method for Agrobacterium-mediated transformation of Arabidopsis thaliana. Plant J. 16, 735-743. doi: 10.1046/j.1365-313x.1998.00343.x 
Contreras Martos, S., Nguyen, H. N., Nguyen, P. N., Hristozova, N., MacossayCastillo, M., Kovacs, D., et al. (2018). Quantification of intrinsically disordered proteins: a problem not fully appreciated. Front. Mol. Biosci. 5, 83. doi: 10.3389/ fmolb.2018.00083

Costa, M. C. D., Artur, M.a.S., Maia, J., Jonkheer, E., Derks, M. F. L., Nijveen, H., et al. (2017). A footprint of desiccation tolerance in the genome of Xerophyiita viscosa. Nat. Plants 3, 17038. doi: 10.1038/nplants.2017.38

Costa, M. C. D., Farrant, J. M., Oliver, M. J., Ligterink, W., Buitink, J., and Hilhorst, H.M. W. (2016). Key genes involved in desiccation tolerance and dormancy across life forms. Plant Sci. 251, 162-168. doi: 10.1016/j.plantsci.2016.02.001

Cuevas-Velazquez, C. L., Reyes, J. L., and Covarrubias, A. A. (2017). Group 4 late embryogenesis abundant proteins as a model to study intrinsically disordered proteins in plants. Plant Signaling Behav. 12, e1343777. doi: 10.1080/15592324.2017.1343777

Cuevas-Velazquez, C. L., Saab-Rincon, G., Reyes, J. L., and Covarrubias, A. A. (2016). The unstructured N-terminal region of Arabidopsis group 4 late embryogenesis abundant (LEA) proteins is required for folding and for chaperone-like activity under water deficit. J. Biol. Chem. 291, 10893-10903. doi: 10.1074/jbc.M116.720318

Das, R. K., Ruff, K. M., and Pappu, R. V. (2015). Relating sequence encoded information to form and function of intrinsically disordered proteins. Curr. Opin. Struct. Biol. 32, 102-112. doi: 10.1016/j.sbi.2015.03.008

Dekkers, B. J., Willems, L., Bassel, G. W., Van Bolderen-Veldkamp, R. P., Ligterink, W., Hilhorst, H. W., et al. (2012). Identification of reference genes for RT-qPCR expression analysis in Arabidopsis and tomato seeds. Plant Cell Physiol. 53, 28-37. doi: $10.1093 /$ pcp/pcr113

Disfani, F. M., Hsu, W. L., Mizianty, M. J., Oldfield, C. J., Xue, B., Dunker, A. K., et al. (2012). MoRFpred, a computational tool for sequence-based prediction and characterization of short disorder-to-order transitioning binding regions in proteins. Bioinformatics 28, I75-I83. doi: 10.1093/ bioinformatics/bts209

Dosztányi, Z., Csizmok, V., Tompa, P., and Simon, I. (2005). IUPred: web server for the prediction of intrinsically unstructured regions of proteins based on estimated energy content. Bioinformatics 21, 3433-3434. doi: 10.1093/ bioinformatics/bti541

Drira, M., Saibi, W., Amara, I., Masmoudi, K., Hanin, M., and Brini, F. (2015). Wheat dehydrin K-segments ensure bacterial stress tolerance, antiaggregation and antimicrobial effects. Appl. Biochem. Biotechnol. 175, 3310-3321. doi: 10.1007/s12010-015-1502-9

Dunker, A. K., Lawson, J. D., Brown, C. J., Williams, R. M., Romero, P., Oh, J. S., et al. (2001). Intrinsically disordered protein. J. Mol. Graphics Modell. 19, 26-59. doi: 10.1016/S1093-3263(00)00138-8

Dure, L., 3rd, Crouch, M., Harada, J., Ho, T. H., Mundy, J., Quatrano, R., et al. (1989). Common amino acid sequence domains among the LEA proteins of higher plants. Plant Mol. Biol. 12, 475-486. doi: 10.1007/BF00036962

Dure, L., Greenway, S. C., and Galau, G. A. (1981). Developmental biochemistry of cottonseed embryogenesis and germination-changing messenger ribonucleicacid populations as shown by in vitro and in vivo protein-synthesis.14. Biochemistry 20, 4162-4168. doi: 10.1021/bi00517a033

Dyson, H. J., and Wright, P. E. (2002). Coupling of folding and binding for unstructured proteins. Curr. Opin. Struct. Biol. 12, 54-60. doi: 10.1016/ S0959-440X(02)00289-0

Dyson, H. J., and Wright, P. E. (2005). Intrinsically unstructured proteins and their functions. Nat. Rev. Mol. Cell Biol. 6, 197-208. doi: 10.1038/nrm1589

Espelund, M., Saeboelarssen, S., Hughes, D. W., Galau, G. A., Larsen, F., and Jakobsen, K. S. (1992). Late embryogenesis-abundant genes encoding proteins with different numbers of hydrophilic repeats are regulated differentially by abscisic-acid and osmotic-stress. Plant J. 2, 241-252. doi: 10.1111/j.1365-313X.1992.00241.x

Farrant, J. M., Cooper, K., Hilgart, A., Abdalla, K. O., Bentley, J., Thomson, J. A., et al. (2015). A molecular physiological review of vegetative desiccation tolerance in the resurrection plant Xerophyta viscosa (Baker). Planta 242, 407-426. doi: 10.1007/s00425-015-2320-6

Farrant, J. M., Cooper, K., and Nell, H. (2012). "Desiccation tolerance," in Plant Stress Physiology. Eds. S. Shabala (Wallingford, CT: CAB International), 238265. doi: $10.1079 / 9781845939953.0238$

Farrant, J. M., and Moore, J. P. (2011). Programming desiccation-tolerance: from plants to seeds to resurrection plants. Curr. Opin. Plant Biol. 14, 340-345. doi: 10.1016/j.pbi.2011.03.018
Furuki, T., and Sakurai, M. (2016). Group 3 LEA protein model peptides protect enzymes against desiccation stress. Biochim. Biophys. Acta-Proteins Proteomics 1864, 1237-1243. doi: 10.1016/j.bbapap.2016.04.012

Gaff, D. F., and Oliver, M. (2013). The evolution of desiccation tolerance in angiosperm plants: a rare yet common phenomenon. Funct. Plant Biol. 40, 315-328. doi: 10.1071/FP12321

Galau, G. A., Bijaisoradat, N., and Hughes, D. W. (1987). Accumulation kinetics of cotton late embryogenesis-abundant messenger-rnas and storage protein messenger-Rnas-coordinate regulation during embryogenesis and the role of abscisic-acid. Dev. Biol. 123, 198-212. doi: 10.1016/0012-1606(87)90442-8

Galau, G. A., Hughes, D. W., and Dure, L. (1986). Abscisic-acid induction of cloned cotton late embryogenesis-abundant (Lea) Messenger-Rnas. Plant Mol. Biol. 7, 155-170. doi: 10.1007/BF00021327

Gao, J., and Lan, T. (2016). Functional characterization of the late embryogenesis abundant (LEA) protein gene family from Pinus tabuliformis (Pinaceae) in Escherichia coli. Sci. Rep. 6, 19467. doi: 10.1038/srep19467

Gekko, K., Ohmae, E., Kameyama, K., and Takagi, T. (1998). Acetonitrileprotein interactions: amino acid solubility and preferential solvation. Biochim. Biophys. Acta-Protein Struct. Mol. Enzymol. 1387, 195-205. doi: 10.1016/ S0167-4838(98)00121-6

Goyal, K., Walton, L. J., Browne, J. A., Burnell, A. M., and Tunnacliffe, A. (2005a). Molecular anhydrobiology: identifying molecules implicated in invertebrate anhydrobiosis. Integr. Comp. Biol. 45, 702-709. doi: 10.1093/icb/45.5.702

Goyal, K., Walton, L. J., and Tunnacliffe, A. (2005b). LEA proteins prevent protein aggregation due to water stress. Biochem. J. 388, 151-157. doi: 10.1042/BJ20041931

Greenfield, N. J. (2006). Using circular dichroism spectra to estimate protein secondary structure. Nat. Protoc. 1, 2876-2890. doi: 10.1038/nprot.2006.202

Grossman, T. H., Kawasaki, E. S., Punreddy, S. R., and Osburne, M. S. (1998). Spontaneous cAMP-dependent derepression of gene expression in stationary phase plays a role in recombinant expression instability. Gene 209, 95-103. doi: 10.1016/S0378-1119(98)00020-1

Halder, T., Upadhyaya, G., and Ray, S. (2017). YSK2 Type dehydrin (SbDhn1) from sorghum bicolor showed improved protection under high temperature and osmotic stress condition. Front. Plant Sci. 8, 918. doi: 10.3389/fpls.2017.00918

Hernandez-Sanchez, I. E., Maruri-Lopez, I., Graether, S. P., and Jimenez-Bremont, J. F. (2017). In vivo evidence for homo- and heterodimeric interactions of Arabidopsis thaliana dehydrins AtCOR47, AtERD10, and AtRAB18. Sci. Rep. 7, 17036. doi: 10.1038/s41598-017-15986-2

Heyen, B. J., Alsheikh, M. K., Smith, E. A., Torvik, C. F., Seals, D. F., and Randall, S. K. (2002). The calcium-binding activity of a vacuole-associated, dehydrin-like protein is regulated by phosphorylation. Plant Physiol. 130, 675-687. doi: 10.1104/pp.002550

Hincha, D. K., and Thalhammer, A. (2012). LEA proteins: IDPs with versatile functions in cellular dehydration tolerance. Biochem. Soc. Trans. 40, 10001003. doi: $10.1042 / B S T 20120109$

Hoekstra, F. A., Golovina, E. A., and Buitink, J. (2001). Mechanisms of plant desiccation tolerance. Trends Plant Sci. 6, 431-438. doi: 10.1016/ S1360-1385(01)02052-0

Holehouse, A. S., Das, R. K., Ahad, J. N., Richardson, M. O., and Pappu, R. V. (2017). CIDER: Resources to analyze sequence-ensemble relationships of intrinsically disordered proteins. Biophys. J. 112, 16-21. doi: 10.1016/j.bpj.2016.11.3200

Hu, T. Z., Zhou, N., Fu, M. L., Qin, J., and Huang, X. Y. (2016). Characterization of OsLEAla and its inhibitory effect on the resistance of E. coli to diverse abiotic stresses. Int. J. Biol. Macromol. 91, 1010-1017. doi: 10.1016/j.ijbiomac. 2016.06.056

Hughes, D. W., and Galau, G. A. (1991). Developmental and Environmental Induction of Lea and Leaa Messenger-Rnas and the Postabscission Program during Embryo Culture. Plant Cell 3, 605-618. doi: 10.1105/tpc.3.6.605

Hundertmark, M., Buitink, J., Leprince, O., and Hincha, D. K. (2011). The reduction of seed-specific dehydrins reduces seed longevity in Arabidopsis thaliana. Seed Sci. Res. 21, 165-173. doi: 10.1017/S0960258511000079

Hundertmark, M., and Hincha, D. K. (2008). LEA (Late Embryogenesis Abundant) proteins and their encoding genes in Arabidopsis thaliana. BMC Genomics 9., 118. doi: 10.1186/1471-2164-9-118

Hundertmark, M., Popova, A. V., Rausch, S., Seckler, R., and Hincha, D. K. (2012). Influence of drying on the secondary structure of intrinsically disordered and globular proteins. Biochem. Biophys. Res. Commun. 417, 122-128. doi: $10.1016 /$ j.bbrc.2011.11.067 
Iakoucheva, L. M., Radivojac, P., Brown, C. J., O'connor, T. R., Sikes, J. G., Obradovic, Z., et al. (2004). The importance of intrinsic disorder for protein phosphorylation. Nucleic Acids Res. 32, 1037-1049. doi: 10.1093/nar/gkh253

Illing, N., Denby, K. J., Collett, H., Shen, A., and Farrant, J. M. (2005). The signature of seeds in resurrection plants: A molecular and physiological comparison of desiccation tolerance in seeds and vegetative tissues. Integr. Comp. Biol. 45, 771-787. doi: 10.1093/icb/45.5.771

Ingram, J., and Bartels, D. (1996). The molecular basis of dehydration tolerance in plants. Annu. Rev. Plant Physiol. Plant Mol. Biol. 47, 377-403. doi: 10.1146/ annurev.arplant.47.1.377

Jiang, S. J., Wang, J., Liu, X. L., Liu, Y. Y., Guo, C., Zhang, L. W., et al. (2017). DrwH, a novel WHy domain-containing hydrophobic LEA5C protein from Deinococcus radiodurans, protects enzymatic activity under oxidative stress. Sci. Rep. 7, 9281. doi: 10.1038/s41598-017-09541-2

Joosen, R. V. L., Kodde, J., Willems, L.a.J., Ligterink, W., Van Der Plas, L. H. W., and Hilhorst, H. W. M. (2010). GERMINATOR: a software package for highthroughput scoring and curve fitting of Arabidopsis seed germination. Plant J. 62, 148-159. doi: 10.1111/j.1365-313X.2009.04116.X

Karimi, M., Inzé, D., and Depicker, A. (2002). GATEWAY vectors for Agrobacterium-mediated plant transformation. Trends Plant Sci. 7, 193-195. doi: 10.1016/S1360-1385(02)02251-3

Kovacs, D., Kalmar, E., Torok, Z., and Tompa, P. (2008). Chaperone activity of ERD10 and ERD14, two disordered stress-related plant proteins. Plant Physiol. 147, 381-390. doi: 10.1104/pp.108.118208

Kozlowski, L. P. (2016). IPC-Isoelectric Point Calculator. Biol. Direct 11, 55. doi: 10.1186/s13062-016-0159-9

Leprince, O., and Buitink, J. (2010). Desiccation tolerance: From genomics to the field. Plant Sci. 179, 554-564. doi: 10.1016/j.plantsci.2010.02.011

Leprince, O., Hendry, G., and Mckersie, B. (1993). The mechanisms of desiccation tolerance in developing seeds. Seed Sci. Res. 3, 231-246. doi: 10.1017/ S0960258500001859

Ling, H., Zeng, X., and Guo, S. (2016). Functional insights into the late embryogenesis abundant (LEA) protein family from Dendrobium officinale (Orchidaceae) using an Escherichia coli system. Sci. Rep. 6, 39693. doi: 10.1038/srep39693

Liu, Y., Liang, J., Sun, L., Yang, X., and Li, D. (2016). Group 3 LEA Protein, ZmLEA3, Is Involved in Protection from Low Temperature Stress. Front. Plant Sci. 7, 1011. doi: 10.3389/fpls.2016.01011

Liu, Y., Yang, M. Y., Cheng, H., Sun, N., Liu, S. M., Li, S. M., et al. (2017). Z The effect of phosphorylation on the salt-tolerance-related functions of the soybean protein PM18, a member of the group-3 LEA protein family. Biochim. Biophys. Acta-Proteins Proteomics 1865, 1291-1303. doi: 10.1016/j.bbapap.2017.08.020

Lopes, J. L., Miles, A. J., Whitmore, L., and Wallace, B. A. (2014). Distinct circular dichroism spectroscopic signatures of polyproline II and unordered secondary structures: applications in secondary structure analyses. Protein Sci. 23, 17651772. doi: $10.1002 /$ pro. 2558

Maia, J., Dekkers, B. J. W., Provart, N. J., Ligterink, W., and Hilhorst, H. W. M. (2011). The re-establishment of desiccation tolerance in germinated Arabidopsis thaliana seeds and its associated transcriptome. PLoS One 6, e29123. doi: 10.1371/journal.pone.0029123

Mello-Silva, R., Santos, D.Y.A.C., Salatino, M. L. F., Motta, L. B., Cattai, M. B., Sasaki, D., et al. (2011). Five vicarious genera from Gondwana: the Velloziaceae as shown by molecules and morphology. Ann. Bot. 108, 87-102. doi: 10.1093/ aob/mcr 107

Mohan, A., Oldfield, C. J., Radivojac, P., Vacic, V., Cortese, M. S., Dunker, A. K., et al. (2006). Analysis of molecular recognition features (MoRFs). J. Mol. Biol. 362, 1043-1059. doi: 10.1016/j.jmb.2006.07.087

Mouillon, J. M., Gustafsson, P., and Harryson, P. (2006). Structural investigation of disordered stress proteins. Comparison of full-length dehydrins with isolated peptides of their conserved segments. Plant Physiol. 141, 638-650. doi: 10.1104/pp.106.079848

Nakamura, S., Mano, S., Tanaka, Y., Ohnishi, M., Nakamori, C., Araki, M., et al. (2010). Gateway binary vectors with the bialaphos resistance gene, bar, as a selection marker for plant transformation. Biosci. Biotechnol. Biochem. 74, 1315-1319. doi: 10.1271/bbb.100184

Nakayama, K., Okawa, K., Kakizaki, T., Honma, T., Itoh, H., and Inaba, T. (2007). Arabidopsis Cor15am is a chloroplast stromal protein that has cryoprotective activity and forms oligomers. Plant Physiol. 144, 513-523. doi: 10.1104/ pp.106.094581

Nelson, J. C., Saven, J. G., Moore, J. S., and Wolynes, P. G. (1997). Solvophobically driven folding of nonbiological oligomers. Science 277, 1793-1796. doi: 10.1126/science.277.5333.1793

Oldfield, C. J., Cheng, Y. G., Cortese, M. S., Romero, P., Uversky, V. N., and Dunker, A. K. (2005). Coupled folding and binding with alpha-helix-forming molecular recognition elements. Biochemistry 44, 12454-12470. doi: 10.1021/ bi050736e

Oliver, M. J., Tuba, Z., and Mishler, B. D. (2000). The evolution of vegetative desiccation tolerance in land plants. Plant Ecol. 151, 85-100. doi: 10.1023/A:1026550808557

Popova, A. V., Hundertmark, M., Seckler, R., and Hincha, D. K. (2011). Structural transitions in the intrinsically disordered plant dehydration stress protein LEA7 upon drying are modulated by the presence of membranes. Biochim. Biophys. Acta-Biomembr. 1808, 1879-1887. doi: 10.1016/j.bbamem.2011.03.009

Popova, A. V., Rausch, S., Hundertmark, M., Gibon, Y., and Hincha, D. K. (2015). The intrinsically disordered protein LEA7 from Arabidopsis thaliana protects the isolated enzyme lactate dehydrogenase and enzymes in a soluble leaf proteome during freezing and drying. Biochim. Biophys. Acta-Proteins Proteomics 1854, 1517-1525. doi: 10.1016/j.bbapap.2015.05.002

Porembski, S. (2011). "Evolution, diversity, and habitats of poikilohydrous vascular plants," in Plant desiccation tolerance (Berlin: Springer), 139-156. doi: 10.1007/978-3-642-19106-0_8

Porembski, S., and Barthlott, W. (2000). Granitic and gneissic outcrops (inselbergs) as centers of diversity for desiccation-tolerant vascular plants. Plant Ecol. 151, 19-28. doi: 10.1023/A:1026565817218

Rakhra, G., Kaur, T., Vyas, D., Sharma, A. D., Singh, J., and Ram, G. (2017). Molecular cloning, characterization, heterologous expression and in-silico analysis of disordered boiling soluble stress-responsive wBsSRP protein from drought tolerant wheat cv.PBW 175. Plant Physiol. Biochem. 112, 29-44. doi: 10.1016/j.plaphy.2016.12.017

Reed, R. G., Feldhoff, R. C., Clute, O. L., and Peters, T. (1975). Fragments of Bovine Serum-Albumin Produced by Limited Proteolysis - Conformation and LigandBinding. Biochemistry 14, 4578-4583. doi: 10.1021/bi00692a004

Rensing, S. A., Lang, D., Zimmer, A. D., Terry, A., Salamov, A., Shapiro, H., et al. (2008). The Physcomitrella genome reveals evolutionary insights into the conquest of land by plants. Science 319, 64-69. doi: 10.1126/ science. 1150646

Reyes, J. L., Campos, F., Wei, H., Arora, R., Yang, Y., Karlson, D. T., et al. (2008). Functional dissection of hydrophilins during in vitro freeze protection. Plant Cell Environ. 31, 1781-1790. doi: 10.1111/j.1365-3040.2008.01879.x

Riera, M., Figueras, M., Lopez, C., Goday, A., and Pages, M. (2004). Protein kinase CK2 modulates developmental functions of the abscisic acid responsive protein Rab17 from maize. Proc. Nat. Acad. Sci. U. S. A. 101, 9879-9884. doi: 10.1073/pnas.0306154101

Rivera-Najera, L. Y., Saab-Rincon, G., Battaglia, M., Amero, C., Pulido, N. O., Garcia-Hernandez, E., et al. (2014). A Group 6 late embryogenesis abundant protein from common bean is a disordered protein with extended helical structure and oligomer-forming properties. J. Biol. Chem. 289, 31995-32009. doi: $10.1074 /$ jbc.M114.583369

Saucedo, A. L., Hernandez-Dominguez, E. E., De Luna-Valdez, L. A., GuevaraGarcia, A. A., Escobedo-Moratilla, A., Bojorquez-Velazquez, E., et al. (2017). Insights on structure and function of a late embryogenesis abundant protein from Amaranthus cruentus: an intrinsically disordered protein involved in protection against desiccation, oxidant conditions, and osmotic stress. Front. Plant Sci. 8, 497. doi: 10.3389/fpls.2017.00497

Scott, P. (2000). Resurrection plants and the secrets of eternal leaf. Ann. Bot. 85, 159-166. doi: 10.1006/anbo.1999.1006

Sharma, A., Kumar, D., Kumar, S., Rampuria, S., Reddy, A. R., and Kirti, P. B. (2016). Ectopic expression of an atypical hydrophobic group 5 LEA protein from wild peanut, Arachis diogoi confers abiotic stress tolerance in tobacco. PLoS One 11, e0150609. doi: 10.1371/journal.pone.0150609

Shi, J., Liu, M. Q., Chen, Y. Z., Wang, J. Y., and Lu, C. F. (2016). Heterologous expression of the dehydrin-like protein gene AmCIP from Ammopiptanthus mongolicus enhances viability of Escherichia coli and tobacco under cold stress. Plant Growth Regul. 79, 71-80. doi: 10.1007/s10725-015-0112-4 
Shi, Z. S., Olson, C. A., Rose, G. D., Baldwin, R. L., and Kallenbach, N. R. (2002). Polyproline II structure in a sequence of seven alanine residues. Proc. Nat. Acad. Sci. U. S. A. 99, 9190-9195. doi: 10.1073/pnas.112193999

Shih, M. D., Hsieh, T. Y., Jian, W. T., Wu, M. T., Yang, S. J., Hoekstra, F. A., et al. (2012). Functional studies of soybean (Glycine max L.) seed LEA proteins GmPM6, GmPM11, and GmPM30 by CD and FTIR spectroscopy. Plant Sci. 196, 152-159. doi: 10.1016/j.plantsci.2012.07.012

Shih, M. D., Hsieh, T. Y., Lin, T. P., Hsing, Y. I. C., and Hoekstra, F. A. (2010). Characterization of Two Soybean (Glycine max L.) LEA IV Proteins by circular dichroism and Fourier transform infrared spectrometry. Plant Cell Physiol. 51, 395-407. doi: 10.1093/pcp/pcq005

Simon, L. M., Kotorman, M., Garab, G., and Laczko, I. (2001). Structure and activity of alpha-chymotrypsin and trypsin in aqueous organic media. Biochem. Biophys. Res. Commun. 280, 1367-1371. doi: 10.1006/bbrc.2001.4282

Soulages, J. L., Kim, K., Walters, C., and Cushman, J. C. (2002). Temperatureinduced extended helix/random coil transitions in a group 1 late embryogenesis-abundant protein from soybean. Plant Physiol. 128, 822-832. doi: 10.1104/pp.010521

Tolleter, D., Jaquinod, M., Mangavel, C., Passirani, C., Saulnier, P., Manon, S., et al. (2007). Structure and function of a mitochondrial late embryogenesis abundant protein are revealed by desiccation. Plant Cell 19, 1580-1589. doi: 10.1105/tpc.107.050104

Tompa, P. (2002). Intrinsically unstructured proteins. Trends Biochem. Sci. 27, 527-533. doi: 10.1016/S0968-0004(02)02169-2

Tompa, P. (2012). Intrinsically disordered proteins: a 10-year recap. Trends Biochem. Sci. 37, 509-516. doi: 10.1016/j.tibs.2012.08.004

Tunnacliffe, A., and Wise, M. J. (2007). The continuing conundrum of the LEA proteins. Naturwissenschaften 94, 791-812. doi: 10.1007/s00114-007-0254-y

Uversky, V. N. (2002). Natively unfolded proteins: A point where biology waits for physics. Protein Sci. 11, 739-756. doi: 10.1110/ps.4210102

Uversky, V. N. (2009). Intrinsically disordered proteins and their environment: effects of strong denaturants, temperature, $\mathrm{pH}$, counter ions, membranes, binding partners, osmolytes, and macromolecular crowding. Protein J. 28, 305-325. doi: 10.1007/s10930-009-9201-4

Uversky, V. N., Gillespie, J. R., and Fink, A. L. (2000). Why are "natively unfolded" proteins unstructured under physiologic conditions? Proteins-Struct. Funct. Genet. 41, 415-427. doi: 10.1002/1097-0134(20001115)41:3<415::AIDPROT130>3.3.CO;2-Z

Venyaminov, S. Y., Baikalov, I. A., Shen, Z. M., Wu, C. S. C., and Yang, J. T. (1993). Circular Dichroic Analysis of Denatured Proteins - Inclusion of Denatured Proteins in the Reference Set. Anal. Biochem. 214, 17-24. doi: 10.1006/ abio. 1993.1450

Verdier, J., Lalanne, D., Pelletier, S., Torres-Jerez, I., Righetti, K., Bandyopadhyay, K., et al. (2013). A regulatory network-based approach dissects late maturation processes related to the acquisition of desiccation tolerance and longevity of Medicago truncatula seeds. Plant Physiol. 163, 757-774. doi: 10.1104/ pp.113.222380

Vicré,M.,Farrant,J.M., andDriouich,A. (2004).Insightsintothecellularmechanisms of desiccation tolerance among angiosperm resurrection plant species. Plant Cell Environ. 27, 1329-1340. doi: 10.1111/j.1365-3040.2004.01212.x

Wan, C. Y., and Wilkins, T. A. (1994). A Modified Hot Borate Method Significantly Enhances the Yield of High-Quality Rna from Cotton (Gossypium-Hirsutum L). Anal. Biochem. 223, 7-12. doi: 10.1006/abio.1994.1538

Wang, X. Y., Zhang, L. S., Zhang, Y. N., Bai, Z. Q., Liu, H., and Zhang, D. P. (2017). Triticum aestivum WRAB18 functions in plastids and confers abiotic stress tolerance when overexpressed in Escherichia coli and Nicotiania benthamiana. PLoS One 12, e0171340. doi: 10.1371/journal.pone.0171340

Whitmore, L., and Wallace, B. A. (2004). DICHROWEB, an online server for protein secondary structure analyses from circular dichroism spectroscopic data. Nucleic Acids Res. 32, W668-W673. doi: 10.1093/nar/gkh371

Wodniok, S., Brinkmann, H., Glockner, G., Heidel, A. J., Philippe, H., Melkonian, M., et al. (2011). Origin of land plants: do conjugating green algae hold the key? BMC Evol. Biol. 11, 104. doi: 10.1186/1471-2148-11-104

Zhang, X., Lu, S. C., Jiang, C. H., Wang, Y. F., Lv, B., Shen, J. B., et al. (2014). RcLEA, a late embryogenesis abundant protein gene isolated from Rosa chinensis, confers tolerance to Escherichia coli and Arabidopsis thaliana and stabilizes enzyme activity under diverse stresses. Plant Mol. Biol. 85, 333-347. doi: 10.1007/s11103-014-0192-y

Zhang, Z., Kuipers, G., Niemiec, L., Baumgarten, T., Slotboom, D. J., De Gier, J. W., et al. (2015). High-level production of membrane proteins in E-coli BL21(DE3) by omitting the inducer IPTG. Microb. Cell Fact. 14, 142. doi: 10.1186/ s12934-015-0328-Z

Zhou, Y., He, P., Xu, Y. P., Liu, Q., Yang, Y. G., and Liu, S. Q. (2017). Overexpression of CsLEA11, a Y3SK2-type dehydrin gene from cucumber (Cucumis sativus), enhances tolerance to heat and cold in Escherichia coli. AMB Express 7, 182. doi: 10.1186/s13568-017-0483-1

Conflict of Interest: The authors declare that the research was conducted in the absence of any commercial or financial relationships that could be construed as a potential conflict of interest.

Copyright ( 2019 Artur, Rienstra, Dennis, Farrant, Ligterink and Hilhorst. This is an open-access article distributed under the terms of the Creative Commons Attribution License (CC BY). The use, distribution or reproduction in other forums is permitted, provided the original author(s) and the copyright owner(s) are credited and that the original publication in this journal is cited, in accordance with accepted academic practice. No use, distribution or reproduction is permitted which does not comply with these terms. 